\title{
Die Flußauen in der schweizerischen Kulturlandschaft
}

\author{
Eduard Gerber
}

Die Arbeit ist dem Andenken an Dr. Rudolf Siegrist und Prof. Dr. Hans Pallmann gewidmet, die beide im Jahre 1965 kurz nacheinander starben. Siegrist hat seinerzeit bei Prof. Carl Schröter über Auenwälder doktoriert und später als National- und aargauischer Regierungsrat aktiv an der Gewässerpolitik teilgenommen. Auf seine Initiative wurde mit Mitteln von Elektrizitätswerken, deren Bau die schweizerischen Flußauen grundlegend veränderte, der «Fonds zur Erforschung der Pflanzengesellschaften schweizerischer Flußauen» ins Leben gerufen. Dieser Fonds ermöglichte die Finanzierung einer Reihe von Arbeiten über Pflanzengesellschaften, über die Böden und die forstlichen Verhältnisse der Auenwälder (siehe Literaturverzeichnis). Auf seine Anregung geht auch die vorliegende Arbeit zurück. Pallmann, ehemaliger Professor der Bodenkunde und ein guter Botaniker (wie Siegrist Schüler von Schröter), war während seiner Amtszeit als Schulratspräsident Vorsitzender der Kuratel des Fonds und ein eifriger Förderer der wissenschaftlichen Arbeiten.

Ganz besonderen Dank schulde ich Herrn G. Gysel, Vizedirektor der NOK, welcher die ins Stocken geratene Publikation (die Arbeit wurde 1962 als Teil eines Sammelwerkes abgeliefert) doch noch zu einem guten Ende brachte, und Herrn Prof. Dr. E. Winkler, der mir wie eh und je in uneigennütziger und freundschaftlicher Art geholfen hat.

\section{Die Landschaft der Flußauen}

Der Begriff Flußaue ist wohl von den Geobotanikern am besten definiert wurden, da die Flußaue durch eine charakteristische Pflanzengesellschaft, die der Auenwälder, besiedelt wird. Diese entsteht, wenn bei Hochwasser vorübergehend die ganze Aue unter Wasser, bei normaler Wasserführung aber trocken liegt. Im verwandten Bruchwald steht das Grundwasser dauernd nahe der Oberfläche. Er stockt auf Bruchwaldtorf, während die typischen Auenwälder an mineralische Sedimente gebunden sind (Ellenberg 1963).

Periodisch überschwemmte Flußgebiete sind auch geographisch ausgezeichnete Gebiete. Sie spielen in der Kulturgeschichte eine hervorragende Rolle. Das markanteste Beispiel bietet Ägypten, wo einzig der periodisch überschwemmte Talboden kultiviert wer- den konnte. Die Überschwemmungen bringen hier dem Boden nicht nur das Wasser; durch Schlammablagerungen wird er immer aufs neue befruchtet. Die Kulturlandschaft reicht so weit, als der Nil sich geltend macht.

In unserem Klima erhalten die Hochflächen und Hänge, ja sogar die durchlässigen Schotterterrassen so viele, über das ganze Jahr verteilte Niederschläge, daß auch sie in Kultur genommen werden können. Die Flußauen, deren Flächen bei Hochwasser überschwemmt werden, haben sich dagegen durch lange Zeiten als kulturfeindlich erwiesen. Zwar hat der Mensch immer wieder versucht, in diese Landschaft einzudringen, denn der Boden ist fruchtbar und oft von tiefgründigen Auelehmen überzogen. Aber die Überschwemmungen, die sich im Niltal so segensreich auswirken, haben immer wieder Wiesen und Äcker, Straßen und Häuser zerstört. So haben die Flußauen lange Zeit weitgehend den Charakter urtümlicher, vom Menschen nicht umgestalteter Landschaften bewahren können.

Fast restlos ist die Kultivierung der Flußlandschaften erst in der Neuzeit gelungen. Sie spielte sich in relativ kurzen Phasen ab, sozusagen vor unsern Augen. Noch unsere Großeltern kannten große, kaum genutzte Gebiete.

Die Flußauen bilden wie jede Landschaft einen äußerst verwickelten Komplex von Erde, Wasser, Luft und Lebewesen. Auch wenn sie gut von andersartigen Landschaften abgegrenzt werden können und in sich geschlossen erscheinen, stehen sie doch in mannigfacher Wechselbeziehung zu den Nachbarlandschaften, deren Veränderungen sich unweigerlich auch in ihnen geltend machen. In der bestbehüteten Auenlandschaft wirkt sich die Gewässerverschmutzung aus. Gerade bei den Flußauen zeigen sich auch weitreichende Fernwirkungen. So macht sich in unsern großen Mittellandflüssen der Einfluß der Alpen geltend.

Die ständige Veränderung, der jede Landschaft unterworfen ist, kann sehr langsam verlaufen, aber auch katastrophale, revolutionäre Phasen aufweisen. Oft hat der Mensch versucht, in dieses Geschehen einzugreifen und die Flußauen zu seinem Nutzen umzugestalten. Immer wieder wurde beim $\mathrm{Ab}$ schluß solcher Werke mit Stolz und Zuversicht verkündet, daß nun für die Zukunft der günstige $\mathrm{Zu}$ stand gesichert sei. Aber es gibt kein endgültig abgeschlossenes Werk, auch wenn nach mensch- 
lichem Ermessen ein scheinbar stabiles Gleichgewicht erreicht worden ist. Die Wandlung der Flußauen durch den Menschen, der in eigenartiger Weise als Gestalter wie als integraler Bestandteil mit der Landschaft verflochten ist, gehört zur Kulturgeschichte. Sie kann aber nur verstanden werden, wenn wir die Naturvorgänge kennen, welche in den Flußauen vor sich gehen.

\section{Naturlandschaft und Kulturlandschaft}

Große Schwankungen in der Wasserführung bedingen periodische Überschwemmungen und bilden die Voraussetzung für das Entstehen von Auenwäldern. In der Schweiz sind die Wintermonate im allgemeinen viel niederschlagsärmer als die Sommermonate. Periodische Hochwasser treten, unterstützt durch die alpine Schneeschmelze im Sommer, also während der Vegetationsperiode, auf. Für die Mittellandflüsse, besonders für die Aare, sind indessen auch aperiodische Spitzenhochwasser im Winter charakteristisch; sie treten auf, wenn bei einem Wärmeeinbruch mit starken Regenfällen gleichzeitig der Mittelland- und Voralpenschnee wegschmilzt. In geomorphologischer Hinsicht setzen die Auenwälder Gewässer voraus, die sich im Talgrund nicht oder nur sehr langsam einschneiden oder die im Gegenteil aufschütten und ihr Bett dadurch erhöhen. Große Geschiebelasten und ein geringes Gefälle begünstigen das Ausufern.

Biologisch wirken sich die Überschwemmungen so aus, daß im Auenwald nur Pflanzen gedeihen können, welche das periodische Überschwemmen ertragen. So fehlt in ihm die Buche, welche unter den Laubhölzern des Schweizer Waldes weitaus an der ersten Stelle steht. Mit zunehmender Höhe über dem mittleren Sommerwasser folgen sich im Alpenvorland Weidengebüsch, Weidenwald, Grauerlenwald und Eschenmischwald. In den Alpen verändert sich der Auenwald mit der Höhe und den damit zusammenhängenden klimatischen Veränderungen. $\mathrm{Er}$ findet mit dem Aufhören der Vegetation eine natürliche obere Grenze. Die zur Charakterisierung der Auenwälder auch schon vorgeschlagene Einteilung in Fluß-Oberlauf, -Mittellauf und -Unterlauf erscheint weniger zweckmäßig. Denn die Vorstellung, daß der Oberlauf eine Flußstrecke großen Gefälles bedeutet, in welcher das Gewässer erodiert und grobes Geröll transportiert, stimmt nur sehr bedingt und gibt einen mittleren Zustand wieder, der an sich die Ausbildung von Flußauen nicht zulassen würde. Unsere Alpentäler sind mannigfach gestuft; zwischen Steilstrecken in Engpässen schieben sich bis in höchste Höhen hinauf Flachstrecken in breiten Talkesseln, in denen der Fluß aufschüttet und damit auch immer wieder überschwemmt. Stammt das Talgewässer aus einem Gletscher, so wird ein feinkörniger Schlamm abgelagert, welcher dem Auelehm der Mittellandflüsse kaum nachsteht, wenn er auch mineralischer ist und keine Humusstoffe enthält. Auelehme sind übrigens, wie noch gezeigt werden soll, weitgehend Abschwemmprodukte gerodeter Flächen, also eine Kulturfolge: Bezeichnend für alpine Flußauen sind rasche Veränderungen. Sperrt plötzlich ein Bergsturz einen Talgrund, so kann dahinter eine Aufschüttungsfläche entstehen, und in ihr kann sich ein Auenwald entwickeln; aber ebenso rasch kann das Hindernis wieder zerschnitten werden. Das gleiche gilt für große Schwemmkegel, welche mitten in einer Steilstrecke eine vorübergehende Verflachung entstehen lassen können.

Die ausgedehntesten Flußauen haben sich im Mittelland herausbilden können, wo die breiten Talböden mit ihrem verhältnismäßig geringen Gefälle immer wieder überschwemmt werden. Bei normalem Hochwasser wird hier meist nur ein schmaler Streifen überflutet. Durch stetige kleine, vor allem aber durch katastrophal große Laufänderungen bei Spitzenhochwassern können freilich ganz neue Flächen des Talgrundes zu regelmäßig überschwemmtem Auengebiet werden.

Die natürlichen Bedingungen, die zur Bildung und Umbildung der Auenwälder geführt haben, sind im Verlauf der Jahrtausende mehrmals verändert worden. Funde sowohl aus präglazialen wie interglazialen Auenwäldern bezeugen dies. In der großen Eiszeit wurden die Flußauen in der Schweiz total vernichtet, in der letzten auf kleine Reste dezimiert. Aus ihnen mußten sie in der Nacheiszeit wieder aufgebaut werden.

Was wir heute in den Flußauen vor uns sehen, ist allerdings weit entfernt von einer unbeeinflußten Naturlandschaft. Der heutige Zustand ist wesentlich ein Werk des Menschen und damit ein Element der Kulturlandschaft, die sich in langen Epochen der Geschichte unseres Landes herausgebildet hat. Dabei bleibt klar, daß der Mensch, selbst ein natürliches Wesen, die Landschaft nur im Rahmen der Naturgesetze hat umgestalten können. Kulturlandschaften bilden deshalb keinen absoluten Gegensatz zur Naturlandschaft, vielmehr sind es die der $\mathrm{Na}$ tur des Menschen entsprechenden Landschaften. Alle Eingriffe des Menschen in die Landschaft sind zwiespältig. Sie werden geplant auf Grund unserer Naturkenntnis. Da die Naturvorgänge außergewöhnlich komplex sind, beruht jeder Eingriff auf stark vereinfachten Annahmen. Auch wenn geplante wirtschaftliche Vorteile erreicht werden, stellen sich oft Nebenwirkungen ein, die nicht beabsichtigt waren und die sich weit über den Ort des Eingriffes auswirken. Die Planung kann durch erhöhte Naturkenntnis verbessert werden. Förderung der Naturforschung und der Ingenieurwissenschaften ist eine politische Aufgabe. Die Durchführung gro- 
ßer Werke ist nur durch den persönlichen Einsatz verantwortlicher Männer möglich, die eine zielbewußte Kulturpolitik, in bezug auf die Gewässer eine aktive Gewässerpolitik betreiben. Die Geschichte der Veränderungen der Flußauen in der schweizerischen Kulturlandschaft ist so eng verknüpft mit der politischen Geschichte der Schweiz.

\section{Der Eingriff des Menschen in die Flußauen}

Von der prähistorischen Zeit bis zum ausgehenden Mittelalter

Mit dem Rückzug der eiszeitlichen Gletscher in die Alpen begann sich über das ganze Mittelland und die Voralpen der Wald auszubreiten; er drang zur Postglazialzeit in zunehmendem $\mathrm{Maß}$ auch in die Alpen vor. Die Waldgrenze lag im Spätneolithikum und in der Bronzezeit etwa $300 \mathrm{~m}$ höher als heute., Durch die Pollenanalyse ist die Folge der verschiedenen Waldtypen weitgehend abgeklärt worden. Die ungebändigten Flüsse müssen in den breiten, von ausgedehnten Auenwäldern bedeckten Talböden reichverzweigt dahingeflossen sein.

Die Eingriffe der alt- und mittelsteinzeitlichen Menschen, die sich als Sammler, Jäger und Fischer betätigen, waren bei der damaligen dünnen $\mathrm{Be}$ siedlung (wohl weniger als 1 Bewohner pro Quadratkilometer) so gering, daß für diesen Zustand der Ausdruck "menschenbelebte Naturlandschaft» geprägt wurde. Die Flüsse werden so klar gewesen sein, wie sie die ersten europäischen Siedler in Amerika erlebten, als sie dort in die Gebiete der indianischen Jägervölker eindrangen.

Die jüngere Steinzeit wird definiert durch das Aufkommen von Ackerbau und Viehzucht. Mit dieser grundlegenden Änderung der Wirtschaft begannen die ersten größeren Eingriffe ins Landschaftsbild, die Waldrodungen. Die primitive Wirtschaftsform erforderte relativ große Rodungsflächen. Dies wieder erzeugte Nebenwirkungen, wie die Abschwemmung des Bodens von den entwaldeten Flächen und damit verbunden die Bildung von Auelehmen in den Flußniederungen. Die Siedlungen lagen oft an Gewässern. Sicherlich haben die Menschen, einem Urtrieb folgend, allen Unrat und alle Abfälle ins Wasser geworfen; aber der geringe Anfall bei einer Bevölkerungsdichte von schätzungsweise $1-2$ Menschen auf den Quadratkilometer konnte durch die Selbstreinigung der Flüsse noch mühelos verarbeitet werden.

Mit den Römern drang eine neue Kultur in unser Land ein. $\mathrm{Zu}$ ihr gehörte eine Technik im modernen Sinn. Für den Handel und die militärischen Bedürfnisse wurden Straßen gebaut, die auch Flußläufe querten und durch Brückenköpfe gegen Überschwemmungen gesichert wurden. Die Entwässerung von Sumpfgebieten wurde an die Hand genommen. Aber auch in der Römerzeit wie während des ganzen Mittelalters blieben die Eingriffe in die Flußlandschaften noch verschwindend klein. Es lag auch kein unbedingter Zwang vor, in dies kulturfeindliche Gelände vorzudringen, da sich meist noch andere Siedlungsmöglichkeiten boten.

Von der Römerzeit bis zum ausgehenden Mittelalter vollzog sich der große Eingriff der vielen Rodungen, über die wir im einzelnen wenig wissen, durch die aber die Landschaft des Mittellandes, bis in den Jura und in die Alpentäler hinein, entscheidend umgestaltet wurde. Nach Ellenberg sind Flußkiese des mitteleuropäischen Flachlandes meist bereits im Diluvium abgelagert worden, während der Auelehm großenteils erst in historischer Zeit, nach Beginn der Waldrodungen, entstand. Dieser Lehm wurde nur in den beim Ausufern flach überfluteten Überschwemmungsgebieten, wo das Wasser langsam fließt und durch dichte Pflanzenbestände noch zusätzlich in seinem Lauf gebremst wird, abgelagert. Seine Bildung dürfte mit einer Sukzession von der Weichholz- (Weiden- und Grauerlenwald) zur Hartholzaue (Eschenmischwald) einhergegangen sein. Diese Entwicklung stellt ein hübsches Beispiel für eine vom Menschen zwar verursachte, aber durchaus nicht beabsichtigte Nebenwirkung auf die Naturlandschaft dar.

$\mathrm{Zu}$ Ende des 13. Jahrhunderts, das heißt zur Zeit der Entstehung der ältesten Bünde, dürfte in unserm Lande die Gründung neuer Siedlungen im großen und ganzen abgeschlossen worden sein. Doch wurde um die Dörfer und Städte das Kulturland weiter ausgedehnt, der Wald entsprechend zurückgedrängt. Die ausgedehnten Rodungen waren eine Folge des ständigen Wachstums der Bevölkerung. Für 1300 können für die Schweiz etwa 600000 , für 1500 etwa 800000 bis 850000 Einwohner als wahrscheinlich angenommen werden. Durch unrationell geführte Forst- und Alpwirtschaft, besonders durch die schädliche Waldweide, wurde an den Forsten zunehmend Raubbau getrieben. In der Neuzeit wurde dann der Waldbestand durch die eidgenössischen Forstgesetze von 1876 und 1902 in seinem Umfang gesichert; sie bestimmen, daß die Gesamtausdehnung des Waldareals erhalten bleiben müsse und allfällige Rodungen durch Aufforstungen an geeigneten Orten wettzumachen seien.

Schon früh muß auch in den Flußniederungen gerodet worden sein. Dabei ist wohl zu unterscheiden zwischen der regelmäßig überschwemmten Weichholzaue mit weitverzweigten Altwassern, Kies-, Sand- und Waldinseln und der nur bei Spitzenhochwassern überfluteten Hartholzaue mit den Auelehmböden. Diese weniger gefährdeten Flächen, die aber noch eindeutig zur Flußniederung gehören, mußten zur landwirtschaftlichen Nutzung verlokken. Der Boden ist locker und läßt sich verhältnis- 
mäßig leicht bearbeiten. In trockenen Jahren lassen sich diese Flächen mit dem Wasser kleiner Seitenbäche zudem leicht bewässern. Allerdings sind die Kulturen in Katastrophenjahren gefährdet, wenn nicht ganz große Schutzbauten errichtet werden.

Wie das Vordringen des Bauern in diese ungeschützten Flußauen vor sich ging, soll am Beispiel des Emmentales gezeigt werden.

\section{Flußkorrektionen}

\section{Die Kultivierung der Schachen im Emmental}

Schon lange vor der Formung des heutigen Reliefs der Alpen wurden an deren Rand gewaltige Schuttmassen abgelagert, teilweise als große Schwemmkegel mit grobem Gerölle, teilweise als Sand und Mergel. Diese Massen verfestigten sich zu Nagelfluh und Sandstein mit dazwischengelagerten Mergelbändern. Das Bergland des Oberemmentales ist zwischen den breiten Tälern der Emme und Ilfis vielfach von Seitentälchen zerschnitten. Diese sind eng V-förmig und werden deshalb Gräben genannt. Ihre Hänge verschneiden sich häufig firstförmig zu Eggen. Die steilen Hänge ergeben bei Starkregen große und rasch anschwellende Abflußmengen. Die Nagelfluh liefert dazu viel Kies. Zu Trockenzeiten fließen bei Burgdorf weniger als $1 \mathrm{~m}^{3} / \mathrm{sek}$ im Bett der Emme. Der Fluß erscheint dann als ein Bach in einem viel $\mathrm{zu}$ großen Kiesbett. Bei Hochwasser konnten dagegen schon über $250 \mathrm{~m}^{3} / \mathrm{sek}$ gemessen werden. Berüchtigt sind das ungemein rasche Anschwellen und die vom "Eggiwilfuhrmann", wie die Emme bei Hochwasser genannt wird, mitbewegten Kiesmassen.

Ursprünglich bildete das Emmental ein zusammenhängendes Waldgebiet. Der Mensch begann es erst spät zu besiedeln. Zunächst rodete er die Höhen und die Terrassen der breiten Talgründe. Aber auch im Emmental stieg die Bevölkerungszahl, besonders in den Friedensjahren nach 1532, unentwegt an. In Großhöchstetten wurden 1558/59 102 Bauern- und 29 Taunerfeuerstätten, 1653 dagegen 144 Bauernfeuerstätten (zum Teil nun mit geteilten Gütern) und 128 Taunerfeuerstätten gezählt. Von der Not der armen Bevölkerung können wir uns kaum noch einen Begriff machen. In armseligen Hütten hausten große, kinderreiche Familien. Da die guten Siedlungslagen schon besetzt waren, mußte die Bevölkerung neuen, ungenutzten Boden in Kultur nehmen. Für die Bauern fand er sich an den bewaldeten Hängen, die vielerorts gerodet wurden und wo auf kleinen Verflachungen Siedlungen entstanden; die arme Bevölkerung hielt sich an das "Niemandsland» (allerdings mit staatlicher Oberhoheit) der Schachen, das flache Land der Fluß- niederungen, das fruchtbaren Alluvialboden trägt. Diese Niederungen sind aber bei Hochwasser aufs höchste gefährdet, besonders dann, wenn die Emme ihr Bett durch Geschiebe und mitgeführtes Holz verstopft sieht, verheerend über die Ufer tritt, Kies, Sand und Schlamm ablagert oder ein neues Bett gräbt und fruchtbares Erdreich wegreißt. Solch extreme Hochwasser treten sehr unregelmäßig auf. Sie können jahrzehntelang ausbleiben, sich aber dann innerhalb weniger Jahre folgen.

In diese Talgründe traten nach einem Bericht aus dem Trachselwald-Urbar des Jahres 1569 «vil der armen Tagwanern, die sunst merteils im Land erborn und erzogen, aber mit keinen Gütern verfaßt und huslos gewesen, ir und ir Kindern hochen Notdurft halb... uf Allmenden und Schachen, an Wassern, uf Sandwürfen und Ryßgründen». Sie machten hier ihre "Inschlag, Hofstetten, Bünden und Gärten» und hausten hier "nach ihrem Gevallen, eigens Gwalts, ungefragt und unerlaubt unser gnädigen Herren und ir Vögten.»

Wenn die Ausbreitung von Pflanzen und Tieren in neuen Gebieten einem Naturvorgang entspricht und als solcher studiert werden kann, so spielten bei der Ansiedlung der armen Tauner ganz andere Dinge, vor allem die Staatsgewalt und Politik, eine Rolle. Die Reisgründe, das heißt die durch die Úberschwemmung wandelbaren. Alluviallböden, waren Staatsbesitz, die Kultivierung und Besiedlung dieser Gebiete eine politische Angelegenheit.

So wurden im Emmental die widerrechtlich gemachten Einschläge mit Bodenzins belegt, die Erbpachtleute zum Schwellen verpflichtet und der noch vorhandene Schachenwald mit Bann belegt, damit Holz für das Schwellen vorhanden sei. Auf wiederholtes Bitten der Gemeinden wurde die Regierung dazu gedrängt, alle noch übrigen Reisgründe, Schachen und Allmenden an die Gemeinden und Güterbesitzer abzutreten, wogegen diese unter Staatsautsicht die Schwellenpflicht übernehmen mußten. Dieses Einmischen des Staates in die private Sphäre erwies sich als notwendig; vor den Naturgewalten kann ein Einzelner sich kaum genügend schützen. Wie aber die Geschichte der Schachenbesiedlung zeigt, war einst auch der Staat nicht in der Lage, den Wasserhaushalt eines Flusses wirksam zu beeinflussen. Dies bezeugen die immer wiederkehrenden Überschwemmungskatastrophen, die den Bewohnern Not und Elend brachten - so gegen Ende des 16.Jahrhunderts allein in den Jahren 1570, 1575, 1577,1585 und 1588. Sie waren sicher zum Teil klimabedingt; zum Teil ergaben sie sich aber auch als Folge menschlicher Eingriffe, die neben beabsichtigten Vorteilen eben stets auch schädliche und ungewollte Nebenwirkungen zeitigen. Dies erkannte man bereits im 16. Jahrhundert. Denn nicht nur war der landhungrige Mensch damals in die Schachen eingedrungen, auch die Berge und Hänge wur- 
den «maßlos» entholzt. Noch heute wundern sich die Besucher des Emmentales darüber, wie steilste Hänge nicht nur Weideland, sondern auch Äcker tragen. Auf entwaldeten Hängen fließt aber das Wasser viel schneller ab; immer wieder treten hier auch schwere Abschwemmschäden, ja Verrunsungen auf. Nicht aus Zufall sind gerade im Emmental durch Engler und Burger im bewaldeten Sperbelgraben und im weitgehend entwaldeten Rappengraben die Zusammenhänge zwischen Bewaldung und Abfluß quantitativ untersucht worden.

Neben der Entwaldung wurden damals auch die übertriebene «Einzwängung und Vergräderung des Emmenrunses» als ungünstig bezeichnet und der schädliche Einfluß der Holzflößerei und des «Käse- und Ankentransportes» auf der Emme beklagt. Diese Einsicht führte zu verschiedenen Verordnungen der Obrigkeit, die je nach den Zeitumständen schärfer oder sorgloser gehandhabt wurden. Von 1588 an blieb das Emmental während fast 60 Jahren von größeren Überschwemmungen bewahrt. Aber 1651, 1652, 1673, 1711 und 1721 folgten sich wieder Katastrophen. Bis zum Ende des 19. Jahrhunderts zählt man innert 300 Jahren 56 große Überschwemmungen. Eine davon, die Wassernot vom August 1837, hat durch Jeremias Gotthelf eine unvergängliche Schilderung erfahren.

Die Entwicklung im Emmental zeigt, wie vielgestaltig sich das Vordrängen des Menschen in die Flußauen darbietet. Not und Hunger gaben den ersten Anstoß. Zunächst handelte es sich um ganz eigenmächtige, individuelle Aktionen. Das konnte in einem geordneten Staatswesen nicht geduldet werden. Da auch die Gemeinden meist nur zu Werken fähig sind, die in ihrem beschränkten Interessenkreis liegen, und nur eine übergeordnete Behörde, die eine ganze Talschaft erfaßt, Anordnungen verfügen kann, die über den Eigennutz des Einzelnen und der Gemeinden hinausreichen, mußte hier der Staat eingreifen. Zum Schwellen und zum Dammunterhalt wurden auch die Bauern der weit außerhalb der Schachen liegenden Höfe herangezogen. Je gröBer die Eingriffe, um so weniger genügten die Erfahrungen ider Einheimischen, um so mehr mußten Sachverständige von auswärts beigezogen werden, über deren Anordnungen die Bevölkerung wohl oft genug den Kopf geschüttelt haben mag. Kritische Bemerkungen kann man auch in Gotthelfs "Wassernot» nachlesen: "Bei der Wannenfluh ... nahm (die Emme) den Rest von zirka zwanzigtausend bis dreißigtausend Franken Lehrgeld, welches der gute Stand Bern ihr zahlte, damit sie seine mit zweitausend bis dreitausend Franken besoldeten oder betaggeldeten Ingenieurs schwellen und straßen lehre, in Empfang».

Erst mit dem Ende des 19. Jahrhunderts war die Wasserbautechnik so weit, mit Verbauungen, die mit Staatsbeiträgen finanziert wurden, dauernd $\mathrm{Ab}$ hilfe zu schaffen.

Die Eingriffe des Menschen haben das Bild der Sohle des Emmentals gründlich verändert. Durch Hochwasserdämme hat man den Fluß in ein begradigtes Bett gezwungen. Er fließt nun wie in einem engen Tal zwischen Steilufern und kann nicht mehr ausbrechen, auch wenn er große Geschiebelasten mit sich führt. Noch tragen die Flußniederungen die Flurnamen Schachen und Au; es gibt die Dörfer Trubschachen, Rüegsauschachen, Langnau, Bärau und Äschau, aber Schachen und Auen sind trokkengelegt und entwaldet. Die ehemaligen Überschwemmungsgebiete hat man in intensive Kultur genommen; Wohnbauten, Gewerbe- und Industrieanlagen sind im Schutz der Dämme direkt am Ufer des gezähmten Wildwassers errichtet worden. Wo Waldstreifen dem Flußlauf folgen, entbehren sie heute der periodischen Überschwemmung und sind längst keine Auenwälder mehr. Aus der Naturlandschaft ist die Kulturlandschaft entstanden, die so lange bestehen wird, als Menschen das Menschenwerk unter Kontrolle halten, Schäden beheben und Mängel verbessern.

Noch ist auf die Fernwirkungen hinzuweisen, welche die Emme auf die Aare sowohl flußabwärts wie flußaufwärts ausübte. Die Hochwasser der Emme machen sich weit aareabwärts geltend. Da im Emmental kein Geschiebe mehr abgelagert werden konnte, führte die der Aare übergebene Fracht andererseits zu schweren Stauschäden, die sich aareaufwärts auswirkten. Die sich verschlimmernden Verhältnisse im Seeland, von Solothurn an aufwärts über den Bielersee bis zum Neuenburger- und Murtensee und bis in die Broye- und Orbeebene, waren durch die Emme mitverschuldet. Im Emmental selbst konnten die Geschiebeherde durch Aufforstung und Bachverbauungen verkleinert werden. Eine Sanierung der Juragewässer, ein Werk, das sich über viele Kantone erstreckt, ließ sich nur auf eidgenössischer Ebene durchführen. Bevor wir auf sie zu sprechen kommen, müssen wir ihre Vorläufer kennenlernen.

\section{Große Flußkorrektionen vor 1848}

In der Schweiz nahm die Bevölkerung von rund 800 000-850 000 Einwohnern im Jahre 1500 unentwegt zu; sie zählte ungefähr eine Million im Jahre 1600, 1,2 Millionen im Jahre 1700 und 1,7 Millionen im Jahre 1800. Zur Ernährung dieses Bevölkerungszuwachses mußten neue Anbauflächen gewonnen werden. Das führte auch in vielen Voralpen- und Alpentälern zu Eingriffen in den Naturhaushalt von der Art, wie wir sie eben vom Emmental geschildert haben. Auch steile Hänge wurden gerodet. Die sich entwickelnde Industrie 
benötigte viel Holz als Brennstoff, da man noch über keine Steinkohle verfügte. Schön gewachsenes Alpenholz war ein Exportartikel. Die ungeregelten und unvernünftigen Rodungen hatten indessen schwere Schäden im Gefolge. Es bildeten sich neue Runsen, und dadurch wurden die Talflüsse übermäßig mit Geschiebe belastet. Aus dem 16. und 17. Jahrhundert mehren sich die Klagen über Verwüstungen in den großen Talböden des Alpenvorlandes. Es handelte sich bei diesen Vorgängen um typische Fernwirkungen künstlicher Eingriffe. Die Kulturschäden waren so groß, daß die Selbsthilfe der Bevölkerung nicht mehr genügte. Nur ein wohlgefügtes Staatswesen konnte so groß gewordene Aufgaben meistern.

Eine aktionsfähige Eidgenossenschaft gab es aber vor 1848 noch nicht. So kamen im 18. und in der ersten Hälfte des 19. Jahrhunderts nur zwei Werke von größerer Bedeutung zustande: Die Korrektion der Kander, deren Geschiebeführung Thun und darüber hinaus das Aaretal bis Bern bedrohte - ein Werk, das durch den reichen Stand Bern aus eigenen Mitteln durchgeführt werden konnte - sodann die Linthkorrektion, die unter größten politischen Schwierigkeiten in der Zeit der alten Eidgenossenschaft geplant und dank außergewöhnlichem Einsatz verantwortungsbewußter Männer in der Helvetik ausgeführt wurde.

Bei beiden Unternehmungen handelte es sich um die Ableitung eines Flusses in einen See, damit er sich dort seiner Geschiebelast entledige. Die Idee war nicht neu. Behauptet doch die Sage, daß die Interlakener Mönche die Lütschine in den Brienzersee leiteten, in der Absicht, die Versumpfung des Bödeli zu verhüten. Urkundlich läßt sich dies nicht belegen. Doch ist erwiesen, daß schon im 13. Jahrhundert durch Kloster- und Grundherren Dämme errichtet wurden, um die Lütschine in ihrem Lauf an der Berglehne festzuhalten, damit sie nicht das Bödeli überschwemme.

Die Sage von dieser Ablenkung war auch Escher, dem Promotor der Linthkorrektion bekannt, der als Geognost die ganze Schweiz durchwanderte. Schrieb er doch schon 1803 an seinen Freund Steinmüller: "Die Leitung der Lütschinen in den Brienzersee ist aufs Haar das Gleiche, was man am Wallensee zu thun hat, und jene Arbeit ist 300-400 Jahre alt.»

\section{Die Kanderkorrektion}

Unterhalb Thun mündeten die Kander und aus dem Eriz die Zulg in die Aare. Beide führten dem Hauptfluß große Geschiebemengen zu, die von diesem kaum bewältigt werden konnten. Zudem wurde die Kraft der Aare durch Mühlenwerke in Thun gebrochen. Die Schwemmkegel von Kander und Zulg stauten zeitweise die Aare so stark, daß Keller und
Erdgeschosse der untern Stadtteile von Thun unter Wasser gerieten. Im weiten Umkreis versumpfte das Land, und von der zerfaserten Aare blieben Altwässer und Gießen zurück. Aber auch im Kandertal bis gegen Frutigen und im Simmental bis nach Erlenbach hinauf wurde der Talboden oft überschwemmt. 1640 riß die Aare bei Uttigen Ackerland fort, was zeigt, daß hier bis ins Auengebiet gerodet worden war. Beschädigte Häuser mußten versetzt werden. Uttigen beschuldigte Uetendorf und das gegenüberliegende Heimberg, der Schaden sei durch ihr Schwellen entstanden. Durch die fortschreitende Versumpfung nahmen die Krankheiten zu. Von Überschwemmungen wurden aber auch die untern Quartiere der Stadt Bern heimgesucht.

So setzte man 1698 eine Untersuchungskommission ein; 1710 zog man den Tessiner Morotino aus Locarno und den Stuckleutenant Samuel Bodmer, Geometer in Bern, bei. Letzterer erstellte einen Plan, in dessen Kommentar es über die Kander hieß: «. . . welches dann sehr trüb, dick und schwär umb sich fressend wirt, ... und der obern Aar an Größe und Wilde vielmahl weit überlegen ist: Und wie bekannt, die angrenzenden Landschafften mächtig beschädigt: Also daß etlichen Gemeinden ihre Gütter, Felder und Wälder überschwemmt, welche, was sie ergriffen, hinweg geführt, aller angrentzenden Landschafften Hölzer ruiniert, nicht nur durch Wegschwemmung, sondern durch Erhaltung vieler großer Schwellenen, deren etliche by 5000 Schritt lang sind, und viele dieser unerträglich Arbeit dise angrentzenden Gemeinden zu Nichten gemacht werdend. Aus allen disen Umbständen, die diss Canderwasser verursacht habend meine gnädige Herren, als hoche Landesoberkeit, ein väterlich Einsehn thun wollen, zusehen, ob es mit thun- und nutzlicher were, den Cander wider in Thuner See lassen zu lauffen ...."

Am 1. April 1711 nahmen 150 Mann, die jeden Morgen mit klingendem Spiel zur Arbeit geführt wurden und bis abends $7 \mathrm{Uhr}$ daran verweilten, das Korrektionswerk auf. Selbst ein Feldprediger war ihnen beigegeben. Später wurde beschlossen, für die Reststrecke einen Stollen durch den Strättlighubel zu errichten. Dieser Stollen stürzte dann ein. Ende Juni 1714, als die Kander bereits zum Thunersee abfloß, wurde berichtet, daß sie sich in ganz unvorhergesehener Weise einfresse und die Straße nach Frutigen gefährde. Der Vorgang erfolgte so schnell, daß nicht nur ein Teil der Kander, wie geplant worden war, in den Thunersee floß, sondern nach kurzer Zeit alles Wasser abgeleitet wurde, so daß das alte Kanderbett unterhalb der Anzapfstelle trockenlag und Mühlenwerke stillgelegt wurden. So mußte der 1697 künstlich abgelenkte Glütschbach wieder ins einstige Kanderbett geführt werden.

Da nun das Kander- und Simmenwasser dem See 
zufloß, wurde der Abfluß aus dem Thunersee um ein gutes Viertel vergrößert, so daß der Staat die Mühlenwerke in Thun kaufen und abbrechen mußte, um den Durchfluß zu vergrößern. Vom reißenden Lauf der Aare durch die Stadt wurden Häuser unterspült und eine Brücke gefährdet, so daß sogar die Zurückleitung der Kander in ihr altes Bett erwogen wurde. Allein, hierzu war es zu spät. Die Kander hatte bis 1716, also innert zweier Jahre, ihr Bett an der Ablenkungsstelle schon um $90 \mathrm{Fuß}$ tiefer gelegt.

Durch die Kanderkorrektion veränderte sich das Wasserregime der Aare talabwärts grundlegend. Die Aarequartiere in Bern wurden nicht mehr wie vorher katastrophal überschwemmt. Alte Hochwasserzeichen lagen $10 \mathrm{Fu} 3$ höher als die höchsten aller spätern Marken. Im alten Kanderlauf wurden 650 Jucharten Waldungen gewonnen. Die Grundlage zur Aarekorrektion von Thun bis Bern war gegeben, das Schicksal ausgedehnter Auenwälder damit besiegelt.

\section{Die Linthkorrektion}

Die Linthkorrektion stellt in der Schweiz wohl den bekanntesten Eingriff in die Flußauen dar. Die Kanderkorrektion war das Werk eines Standes der alten Eidgenossenschaft. Sie wurde von einem reichen Staatswesen nach dem Willen der gnädigen Herren und Landesväter in die Wege geleitet. Die Linthkorrektion bildete demgegenüber die erste Unternehmung nationalen Charakters, sie wurde von grundlegender Bedeutung für alle zukünftigen Aufgaben dieser Art. Sie entstand in einer Zeit politischer Leidenschaften, mitten in den Verfassungskämpfen beim Übergang von der aristokratischen Regierungsform zur Volksherrschaft, in der Epoche der Aufklärung. Mit dem Linthwerk ist zudem der Name eines vortrefflichen Mannes verknüpft, jener Hans Conrad Eschers, eines Zeitgenossen Pestalozzis, der wie dieser seine ganze Kraft für die Linderung der Not der Mitmenschen einsetzte.

Die Entwicklung, die zur schlimmen Lage im Linthgebiet führte, kommt grundsätzlich einer Wiederholung jener im Kandertal gleich. Wie die Kander in vorgeschichtlicher Zeit den untern Thunersee aufschüttete, so füllte die Linth den untern Teil des Walensees auf. Auf ihrem eigenen Schuttkegel muß sie den Lauf mehrmals gewechselt haben. Ein Bericht über die Schlacht bei Näfels läßt vermuten, daß sie 1388 in den Walensee floß. Jedenfalls war sie reich verästelt, besonders auch auf ihrem Lauf zum Zürichsee.

Bis ins 18. Jahrhundert hinein sind aus der Gegend keine Klagen über größere Flurverwüstungen festgehalten. Nunmehr aber erblühte im Glarnerland eine neue Industrie, die Verarbeitung von Baum- wolle, die einen starken Holzverbrauch zur Folge hatte. Dazu gesellte sich die Holzausfuhr nach Holland. Ganze Wälder wurden damals geschlagen, ohne daß für Nachwuchs Sorge getragen wurde. Der Raubbau rächte sich mit schlimmen Verheerungen durch Rüfen und Schlipfe, welche das Talgewässer mit Schutt belasteten. Furchtbare Wassernöte erschreckten 1762 und 1764 das Volk im Glarnerland.

Die große Geschiebelast hatte zur Folge, daß die Linth in der zweiten Hälfte des 18. Jahrhunderts bei Ziegelbrücke ihr Bett um 16 Fuß erhöhte, so daß der Spiegel des Walensees durch Stau bedrohlich anstieg und in Walenstadt und Weesen bei Sommerhochwasser die Häuser bis zum ersten Stock unter Wasser standen. Die hauptsächlich betroffenen Gebiete gehörten den damaligen gemeinen Herrschaften Gaster und Sargans an; staatliche Hilfe war also nur, durch Vermittlung des Vogtes, von Beschlüssen der Tagsatzung zu erhoffen. Diese erwies sich von jeher und erst recht in der damaligen Zeit in ihren Entschlüssen als äußerst schwerfällig, ganz besonders was Angelegenheiten der gemeinen Herrschaften betraf.

Landammann Christen von Nidwalden und der bernische Landvogt von Sargans, Wagner, brachten die Klagen der schwer leidenden Bevölkerung vor die Tagsatzung, 1783 schlug die Berner Gesandtschaft ihren Ingenieurhauptmann, den Geometer Andreas Lanz, als Experten vor. Noch im gleichen Jahr lieferte dieser einen Bericht: «Ursache der gegenwärtigen traurigen Lage der Stadt Wallenstadt und des Fleckens Wesen wegen Aufschwellung der Wesenerlinth und des Wallensees.» Darin unterbreitete er vier Vorschläge für die Sanierung; als besten und einzig auf die Dauer sich lohnenden bezeichnete er die Ablenkung der Linth in den Walensee. Der Kostenvoranschlag lautete auf 90000 Gulden.

Das Aufbringen so großer Mittel durch eine locker gebundene Oberherrschaft war eine schwierige Sache, so daß die an Instruktionen gebundenen Gesandten die Vorschläge nur "ad referendum» entgegennahmen. Damit wurde das Projekt auf die lange Bank geschoben. Auch die Aufrufe von Rudolf Meyer aus Aarau in der Helvetischen Gesellschaft (1792) und ein Bericht von Hans Conrad Escher (1796) vermochten in der alten Eidgenossenschaft keine Taten auszulösen. Dabei muß die Not fürchterlich gewesen sein, nicht nur im Walenseegebiet, sondern auch im Glarnerland, wo die Industrie am Ende des 18. Jahrhunderts nach kurzer Blüte darniederlag. Der Aufruf Eschers liest sich wie ein Bericht eines Experten über unterentwickelte Länder:

"Sowie man in die Stadt (Wallenstadt) tritt, sieht man die Erdgeschoße aller Häuser von einer scheußlichen Pfütze, auf der Kröten und verfaulen- 
de Pflanzen herumschwimmen, eingenommen... traurig und matt gehen die Menschen auf hingelegten Brettern zwischen diesem vergifteten Schlamm durch ... Der Einfluß des Úbels auf ihre Natur ist also so groß, daß sie nach den hohen Gewässern des Sommers nicht einmal die Pfützen, die sich in den Erdgeschoßen ihrer stinkenden Wohnungen angelegt haben, ausschöpfen... Oft hör ich eben diesen Zustand der Mattigkeit und Erstorbenheit aller edleren Menschentriebe der Bewohner dieser unglücklichen Gegenden als Gründe aufstellen, unser Mitleiden für diese Menschen zu hemmen und Gleichgültigkeit oder gar Abscheu statt Hilfsbegierde gegen sie zu erwecken. Aber wie ungerecht ist dieser Gesichtspunkt der Sache. Die gütige Natur schuf diese Menschen nicht als halbe Menschen, sondern die Versumpfungen, in denen wir (ihre unmittelbaren Landesherren) sie ersterben lassen, entarten sie so schrecklich ... Freilich rührt die Versumpfung der Gestade des Wallenstadter Sees auch von der Natur her; aber diese gab uns Vernunft, ähnliche üble Einflüsse zu lindern; sie zwingt uns zu gesellschaftlichen Verhältnissen, um unter der Anführung von Stellvertretern oder Landesvätern gegen größere Übel zu wirken. Diese Landesväter sind wir mit unsern Bundesgenossen; folglich trifft uns - nicht diese Elenden - der gewiß richtige Vorwurf, daß wir (durch Sorglosigkeit) die Menschheit in ihrem Verderben lassen.»

Aber die Zeit war damals noch nicht reif für $\mathrm{Ab}$ hilfe. Die alte Eidgenossenschaft ging unter. Auch zur Zeit der Helvetik war die Schweiz, mittellos und durch die französische Fremdherrschaft bedrängt, nicht imstande, das Werk in Angriff zu nehmen; doch erstellte Ingenieur Guisan ein neues Gutachten. Erst in der Mediationszeit, 1804, beschloß man auf Grund des Gutachtens von Escher, das Unternehmen in Angriff zu nehmen; 1807 konnte, nachdem noch der badische Ingenieur Tulla als Sachverständiger beigezogen worden war, die Arbeit aufgenommen werden. Am 8. Mai 1811 floß die Linth in den Walensee und am 17. April 1816 war das Werk vollendet.

Damit war aber das Werk nicht abgeschlossen. Noch mußten die Kanäle zwischen dem Walen- und dem Zürichsee ausgebaut und das ganze Gebiet entsumpft werden, eine Aufgabe, die bis in die Gegenwart reicht. Zur Finanzierung wurden nach dem Plan Eschers Aktien ausgegeben, die aus dem Mehrwertertrag des Bodens zurückbezahlt werden sollten, da der Tagsatzung keine Mittel zur Verfügung standen. Viele dieser Aktien wurden in der Folge dem gemeinnützigen Werk geschenkt. Bis zum Tode von Escher (1823) besorgte eine dreigliedrige Kommission die Geschäfte, dann die Linthpolizeikommission, die auch vom neuen Bundesstaat übernommen wurde. 1862 wurde die Eidgenössische Linthkommission geschaffen. Sie zeigt die typisch schweizerische Mischung von eidgenössischer und kantonaler Beteiligung, die auf die Gemeindeautonomie Rücksicht zu nehmen hat. Nach K. Guggenbühl ist «das Rechtsinstitut der öffentlichen Werke ein der Schweiz eigentümliches Institut; keiner der Nachbarstaaten besitzt es.» In der Eidgenössischen Linthkommission sind der Bund und die vier Kantone Zürich, Schwyz, Glarus und St. Gallen vertreten. Sie beaufsichtigt Betrieb und Unterhalt der Kanäle und Entwässerungsgräben; letzterer wird zum Teil durch Genossenschaften der beteiligten Gemeinden ausgeführt.

Die Linthkorrektion hat für die ganze Landschaft weitreichende Folgen gezeitigt. Schon vor dem Zweiten Weltkrieg hat die Schweizerische Vereinigung für Innenkolonisation ein Meliorationswerk geschaffen, das sich dann zum großen Anbauwerk entwickelte. Heute sind die Meliorationen abgeschlossen. Die eidgenössischen Räte haben noch das Unterhaltsgesetz auszuarbeiten.

\section{Flußkorrektionen in den Alpentälern}

Kander- und Linthkorrektion waren Sonderfälle. Mit verhältnismäßig einfachen Mitteln und für die damalige Zeit erträglichen Kosten konnten die übergroßen Geschiebemassen einem nahen See zugeführt, weite Gebiete saniert und der Kultur erschlossen werden.

Die breiten Talböden, in denen die ins Alpenvorland mündenden Flüsse strömen, sind durch Aufschüttung entstanden. Die meisten Alpenrandseen reichten beim Rückzug der Gletscher viel weiter ins Gebirgsinnere als heute. Der Vorgang der Talbodenaufschüttung ist auch jetzt nicht abgeschlossen. Durch die Zuschüttung der Seen werden die Talböden länger, und zwangsläufig nimmt damit das Gefälle ab, was wiederum zu neuer Alluvion zwingt. Überall, wo in einem Talboden aufgeschüttet wird, muß das Gewässer von Zeit zu Zeit seinen Lauf wechseln. Die ganze Fläche ist also potentielles Flußauengebiet. Die größten Ebenen der Schweiz zeigen diesen Charakter, so die Rheintalebene von Landquart bis zum Bodensee (65 km Länge), die Rhonetalebene von Brig bis zum Genfersee, die nur durch das Bergsturzgebiet von Siders und den Riegel von St. Maurice unterbrochen wird $(120 \mathrm{~km}$ Länge), die Ebenen des Tessins bis zum Langensee, der Aare bis zum Brienzersee, der Reuß bis zum Urnersee.

Wir stellten bereits fest, daß sich durch die zunehmende Bewirtschaftung der alpinen Talgehänge und durch den Raubbau an den Wäldern, vor allem im 16. und 17. Jahrhundert, die Geschiebelasten der Flüsse stark erhöhten, daß in der Folge die Überschwemmungen sich häuften, die wachsende $\mathrm{Be}$ völkerung aber immer mehr in die früher ge- 
miedenen Talböden hinausdrängte. Dies gilt ganz allgemein. Die neuen Kulturflächen konnten nur durch großangelegte und weiträumige Maßnahmen geschützt werden, etwa durch kostspielige Wildbachverbauungen und Wiederaufforstungen, dann durch Flußbegradigungen, Eindämmungen und die Anlage von Hochwasser-Abflußbetten. Für die Erfüllung einer so bedeutsamen Aufgabe bedurfte es gründlich ausgebildeter Fachleute. Sie in der Schweiz selbst auszubilden, war nur auf Grund eines politischen Entscheides möglich. Gestützt auf Art. 22 der Bundesverfassung: "Der Bund ist befugt, eine Universität und eine polytechnische Schule zu errichten", beschlossen daher die eidgenössischen Räte 1854 die Begründung einer polytechnischen Schule, ohne welche die nachfolgenden großen Ingenieurarbeiten am Gewässernetz der Schweiz nicht denkbar geworden wären.

Aber auch für die Beteiligung des Bundes an groBen Aufgaben wurde in der Bundesverfassung von 1848 die rechtliche Grundlage geschaffen. Die Fassung von 1848 (Art. 21) lautete:

"Dem Bunde steht das Recht zu, im Interesse der Eidgenossenschaft oder eines großen Theiles derselben auf Kosten der Eidgenossenschaft öffentliche Werke zu errichten oder die Errichtung derselben zu unterstützen.

$\mathrm{Zu}$ diesem $\mathrm{Zwecke}$ ist er auch befugt, gegen volle Entschädigung das Recht der Expropriation geltend zu machen. Die nähern Bestimmungen hierüber bleiben der Bundesgesetzgebung vorbehalten.»

Es ist sehr aufschlußreich, zu verfolgen, was mit diesem Verfassungsartikel weiter geschah, denn es spiegelt sich in der Entwicklung die zunehmende Bedeutung der eidgenössischen Mitarbeit und die Notwendigkeit, neue Aufgaben gesetzlich zu regeln, wider.

Art. 21 ist in die Bundesverfassung von 1874 als Art. 23 unverändert übernommen worden; in Art. 24 werden nun aber zwei Aufgaben besonders genannt: "Der Bund hat das Recht der Oberaufsicht über die Wasserbau- und Forstpolizei im Hochgebirge».

"Er wird die Korrektion und Verbauung der Wildwasser, sowie die Aufforstung ihrer Quellengebiete unterstützen und die nöthigen schützenden Bestimmungen zur Erhaltung dieser Werke und der schon vorhandenen Waldungen aufstellen.»

1897 wurde im ersten Absatz von Art. 24 das präzisierende "im Hochgebirge» gestrichen und damit die Oberaufsicht auf das ganze Gebiet der Eidgenossenschaft ausgedehnt.

Die Bundesbehörden nahmen die Aufgabe der Gewässerkorrektion tatkräftig an die Hand. Über die Wildbäche im Hochgebirge verfaßte C. Culmann, Professor an der polytechnischen Schule, einen eingehenden Bericht an den Bundesrat.
«Den Anstoß für ein systematisches Vorgehen des Bundes bezüglich solcher Ameliorationsarbeiten bildeten aber die Verheerungen, welche das Ende September 1868 eingetretene Hochwasser vom Wallis bis an die äußerste Ostgrenze der Schweiz in Graubünden auf beiden Seiten der Alpen anrichtete.» (Ad. v. Salis, schweizerischer Oberbaudirektor, 1883.)

Culmann schätzte die Kosten der Wildbachverbauungen auf Fr. 3,5 Millionen, jene der Flußkorrektionen ohne Rhein und Juragewässer auf 5 Millionen Franken und diejenigen der Rhein- und Juragewässerkorrektionen auf 40 Millionen; zusammen kam er auf gegen 50 Millionen Franken. Die für die damalige Zeit gewaltigen Aufwendungen konnten nur aufgebracht werden, wenn den Gemeinden die Kantone und diesen der Bund zu Hilfe kamen.

\section{Die Rhonekorrektion}

Bis über die Mitte des 19. Jahrhunderts hinaus floß die Rhone vielfach verzweigt und verästelt im breiten Talboden des Wallis. Die Ablagerung von Geschiebe ließ sie ihren Lauf immer wieder wechseln, Neben der Hauptströmung blieben Altwasser und Sumpfgebiete zurück. Die Sage berichtet, daß der Freiherr von Turn-Gestelnburg in Sommernächten die Sümpfe zu Füßen seiner Burg mit langen Ruten peitschen ließ, um die Frösche, die ihm durch ihr Gequake den Schlaf raubten, zum Schweigen zu bringen.

Die Überflutungen ließen auch Schlamm zurück, der fruchtbares Ackerland ergab. Die Dörfer und Städte mieden den flachen Talboden; sie wurden auf Schwemmkegeln der Zuflüsse, Siders auf einem Bergsturz und Saillon auf einem Felsrücken, angelegt. Eine nicht abbrechende Kette von Überschwemmungskatastrophen bedrohte alles tiefergelegene Kulturland; aber auch die Siedlungen auf den Schwemmkegeln waren von Murgängen der Wildbäche gefährdet. So ist die Kirche von St. Pierre de Clages, die aus dem 11. Jahrhundert stammt, tief von den Alluvionen der Losentse umschüttet.

Zum Teil waren die Hochwasser wetterbedingt. Als besonders gefährlich erwiesen sich beträchtliche Niederschläge in der Zeit der starken Schnee- und Gletscherschmelze. $\mathrm{Zu}$ diesen Wassermengen gesellten sich Katastrophen nach dem Durchbruch großer Wassermengen, die von einem Gletscher aufgestaut waren. So entleerte sich der Märjelensee immer wieder durch Eistunnels unter dem Aletschgletscher. Durch den seitlich mündenden Allalingletscher wurde im Saasertal der Mattmarksee aufgestaut, dessen Wasser unverhofft den sperrenden Gletscher durchbrachen. Endlich wurde durch abstürzendes Eis des Giétrozgletschers das 
Wasser der Drance de Bagnes bei Mauvoisin aufgestaut; es ergoß sich nach Durchbrüchen verheerend über Martigny ins Rhonetal. Diese Katastrophenherde waren an der Wurzel zu bannen. Sowohl am Märjelensee wie am Mattmarksee suchte man der Gefahr mit dem Bau künstlicher Ableitungsstollen zu begegnen.

Um die Überschwemmungen der Rhone in der Talsohle zu meistern, mußten Dämme erstellt werden. Cullmann erwähnt in seinem Gutachten eine Reihe älterer Anlagen. Ganze Abhilfe vermochten indessen nur Werke zu erbringen, welche die Rhone zwangen, allen Schutt bis zum Genfersee zu transportieren. Die Sumpfgebiete außerhalb der Dämme mußten mit dem Schlammwasser der Rhone, der "Gletschermilch», kolmatiert werden. Der Rhonetalboden hat den Vorteil, daß er durch die groBen Schwemmkegel der Zuflüsse mehrfach gekammert wird. Dämme müssen derart nur von Schwemmkegel zu Schwemmkegel gebaut werden. Bei Dammbrüchen werden nur Teilstücke überschwemmt.

1863 stimmten die eidgenössischen Räte dem Korrektionswerk zu. Die Überschwemmungskatastrophe von 1868 bewirkte eine beschleunigte Ausführung der Arbeiten. Heute fließt die Rhone vom Goms bis zum Genfersee gesichert zwischen natürlichen Steilufern oder zwischen Dämmen. Diese wirken in der weitgeschwungenen, großartigen Landschaft in ihrer zu steifen Geradlinigkeit oft etwas hart. Nur in der Bergsturz- und Schwemmkegelstufe des Pfynwaldes, im Grenzgebiet (fines) zwischen der deutschen und der französischen Sprache, ist der Lauf noch ungebändigt und reich verästelt. Der neugewonnene Kulturboden ist fruchtbar; viele Bodenprofile zeigen vorherrschend glimmerreichen Sand. Der einst von der wilden Rhone und ihren Altwässern und von Sümpfen beherrschte Rhonetalboden ist in eine fruchtbare Kulturlandschaft verwandelt worden. In günstigen Lagen zeugen Spezialkulturen - von Aprikosen, Erdbeeren, Tabak, Tomaten, Spargeln u. a. m. - von intensiver Bewirtschaftung. An einzelnen Stellen sind durch aufsteigendes Kapillarwasser Salzausblühungen entstanden, da durch die geringen Niederschläge der Rhonetalebene der Boden zu wenig ausgewaschen wird. Sie müssen in diesem ehemaligen Flußauen- und Sumpfgebiet! - durch neue Regelung des Grundwasserspiegels bekämpft werden. Auch für Windschutzstreifen an Stelle früherer Auenwälder muß gesorgt werden. Längst sind auch Siedlungen in dem früheren Überschwemmungsgebiet entstanden. Auch Industrieanlagen, wie jene der Lonza bei Visp, die Aluminiumwerke bei Chippis und Steg, die Erdölraffinerie bei Aigle, konnten ungefährdet in die Ebene gebaut werden. Endlich liegen mehrere Flugplätze im breiten Talboden.

\section{Die Rheinkorrektion}

Die Rheintalebene von Landquart bis zum Bodensee ist durch die Ablagerung der großen Geschiebemassen aus dem Bündnerland entstanden. Im Laufe der Zeit, mit dem zunehmenden Vorstoßen des breiten Talbodens in den Bodensee hinein, hat das Gefälle abgenommen, und der Fluß wurde vermehrt zum Aufschottern gezwungen. Auch beim Rhein hat sich wie bei andern Alpenflüssen durch die starke Abholzung im Quellgebiet während des späten Mittelalters und der beginnenden Neuzeit die Geschiebefracht erhöht. So hat sich im mittleren Rheintal eine Talsohlenerhöhung von $4-5 \mathrm{~m}$ in einem Jahrhundert ergeben. Jede Aufschotterung ist zwangsläufig mit dem Ausufern des Flusses, mit Überschwemmungen, Laufwechseln, der Bildung von Altwässern und Sümpfen verbunden. Die groBe Rheintalebene konnte deshalb nur mangelhaft in Kultur genommen werden, denn immer wieder wurden die Menschenwerke gefährdet, ja verwüstet und zerstört.

Als ältestes Zeugnis dafür gilt die Zerstörung der Kirche von Lustenau (1206). 1762 war das Rheintal vom Bodensee bis nach Sargans hinauf von Wasserflächen bedeckt. Da große Schwemmkegel besonders auf der Schweizer Seite fehlen, mangelt auch die günstige Kammerung, wie sie sich im Walliser Rhonetal darbietet. Beim Úberschwemmen werden deshalb viel größere Flächen überflutet als im Wallis. Die Dörfer scheinen ganz an die Hänge gedrängt.

Schon vor dem 16. Jahrhundert wurden im Rheintal Schutzbauten errichtet. Da sich aber bei einem so viel Geschiebe führenden Gewässer die Flußsohle dauernd erhöht, vermochten gewöhnliche Schutzdämme nur mangelhaft Abhilfe zu schaffen. Nur eine auf hydrologischen Kenntnissen beruhende Planung und eine radikale, das ganze Flußgebiet umfassende Korrektion konnten die zunehmende Aufschotterung verhindern und die versumpfte Rheintalebene der Kultur erschließen. Es mußten Hochwasserdämme vorgesehen werden, die auch die größten Abflußmengen fassen. Die Pegelschwankungen sind beim Alpenrhein sehr groß. So wurde bei Diepoldsau innert weniger Stunden ein Anstieg von $30 \mathrm{~m}^{3} / \mathrm{s}$ auf $3000 \mathrm{~m}^{3} / \mathrm{s}$ beobachtet. Das Bett mußte überdies so dimensioniert werden, daß das Geschiebe direkt bis in den Bodensee verfrachtet wird.

Grundlegende Eingriffe in den Wasserhaushalt des Rheintales wurden und werden durch die politischen Verhältnisse erschwert. Denn neben den beiden Kantonen St. Gallen und Graubünden sind noch zwei ausländische Staaten, Österreich und Liechtenstein, Anstößer. Jedes Projekt, das beide Ufer berührt, kann nur auf Grund von Staatsverträgen ausgeführt werden. Erst 1892 gelang es, 
einen Vertrag abzuschließen, der auch die dann realisierten Laufverkürzungen von Diepoldsau und Fußach vorsah.

Mit dem Abschluß dieser Arbeiten schien die Gefahr nach menschlicher Voraussicht gebannt. Aber außergewöhnliche meteorologische Verhältnisse, zunächst Föhn mit Abschmelzen von Neuschnee, dann Starkregen, bewirkten am 25. September 1927 ein Hochwasser, dem die Dämme nicht überall gewachsen waren. Bei. Buchs stand das Wasser nur $40 \mathrm{~cm}$ unter der Dammkrone, und am rechten Ufer erfolgte ein Bruch, der sich bald auf $250 \mathrm{~m}$ erweiterte, wodurch im Fürstentum Liechtenstein auf einer Strecke von $16 \mathrm{~km}$ Land überschwemmt und weiträumig mit Sand und Kies überschüttet wurde. Die in der Folge verstärkten Dämme hielten dagegen dem außergewöhnlichen Hochwasser vom 22. August 1954 mit über $2500 \mathrm{~m}^{3} / \mathrm{s}$ stand; doch wurden durch Rückstau im Gebiet von Sargans große Flächen überschwemmt.

Auch im Rheintal folgte der Flußkorrektion die Melioration, mit der man den Talboden entsumpfte und einer intensiven Nutzung zugänglich machte. Das Heranziehen der letzten Landreserven zum Anbau während des Zweiten Weltkrieges beschleunigte dies Vorhaben. Noch folgt die Landstraße den Hangfußsiedlungen, aber die Eisenbahn wurde im ehemals gefährdeten Talboden gebaut, wo sich zunächst sehr einsam die Bahnhöfe erhoben. Auch die Autobahn entstand im ehemaligen Auengebiet. Langsam dringen aber auch im Rheintal Siedlungen ins alte Ưberschwemmungs- und Sumpfland vor nur zögernd, da der Moorboden schlechter Baugrund ist und nur auf Pfählen gebaut werden kann.

Die so kräftig entwickelte Kulturlandschaft steht und fällt mit dem dauernden Unterhalt der Dämme, denn bei Hochwasser liegt der Wasserspiegel bei Buchs höher als die Dachfirste der benachbarten Häuser. Bund und Kantone müssen deshalb auch mit den beiden Nachbarstaaten ständige Fühlung wahren, soll das große Werk erhalten bleiben.

\section{Ein großes Korrektionswerk im Mittelland: Die Juragewässerkorrektion}

Nicht nur in den Alpentälern, auch im Mittelland waren große Flußgebiete zu korrigieren. Das größte Unternehmen ist die Juragewässerkorrektion. Es verdankt seinen Namen den drei Jurarandseen, dem Neuenburger-, Murten- und dem Bielersee, hat mit dem Juragebirge aber wenig zu tun. An die Seen grenzt Flachland von der Emmemündung unterhalb Solothurns über das Große Moos und die Zihlebene bis zur Orbe- und zur Broyeebene. Das ganze Gebiet ist bei weitem die größte ebene Fläche der Schweiz.
Vor der Korrektion bildete die Aare von ihrem Eintritt ins Große Moos bei Aarberg an bis hinunter nach Solothurn breite Flußauen, durch die sie einen reichverästelten Lauf legte. Bei Hochwasser kam es immer wieder zum Ausufern und zu Laufwechseln. Es konnte nachgewiesen werden, daß die Aare in prähistorischer Zeit vom Schwemmkegel bei Aarberg aus in den Murtensee geflossen sein muß.

Das Gebiet um die drei Jurarandseen wurde früh besiedelt. Pfahlbauten sind von den Ufern aller drei Seen bekannt. Die berühmte Fundstelle von La Tène liegt am Neuenburgersee. In der Nähe des Murtensee entstand Aventicum, Hauptstadt der Helveter und des römischen Helvetiens, südöstlich des Bielersees die keltisch-römische Niederlassung Petinesca. Die Straße Aventicum-Salodurum führte mitten durch das Große Moos. Vom Ende des 16. Jahrhunderts an beginnen die Klagen über zunehmende Überschwemmungen. Deren Ursache ist wohl kaum im Klima zu suchen; viel eher waren die Schäden, die sich ergaben, kulturbedingt. Vor allem die Emme, dann die Schüß aus dem Jura bewirkten mit ihren Anschwemmungen in zunehmendem Maße einen Rückstau. 1651 wird von einem Überschwemmungssee berichtet, der von Biel bis nach Solothurn reichte und dem Namen Seeland alle Ehre machte.

Bereits im Jahre 1784 brachte Ingenieur Lanz, der auch das Linthprojekt ausarbeitete, den Vorschlag ein, die Aare in den Bielersee zu leiten. Aber erst im 19. Jahrhundert wurden die Projektstudien energisch an die Hand genommen. Politische Schwierigkeiten waren bei diesem großen Unternehmen von Anfang an vorhanden; sie erweisen sich bis auf den heutigen Tag als groß, da das ausgedehnte Gebiet Teile der Kantone Bern, Solothurn, Freiburg, Waadt und Neuenburg umfaßt und deren Regierungen sich zunächst unter sich einigen müssen, bevor eidgenössische Hilfe möglich ist.

Für schweizerische Verhältnisse ist typisch, daß nicht von Regierungsseite, sondern durch eine Gruppe initiativer Männer das Projekt vorangetrieben wurde. Das Hauptverdienst fiel dabei dem Arzt Dr. Johann Rudolf Schneider aus Nidau zu, der 1835 schrieb: "Es kann und soll auch dieses Werk der Entsumpfung nicht ein Werk der Gnade von Regenten sein, wie ähnliche Unternehmen, die in monarchischen Staaten auf den Wink des Herrschers ausgeführt werden. Das ist eben sein Wert, daß der Boden der Überzeugung gegründet und durch die gemeinsame Kraft edler Männer eines freien Volkes ausgeführt und daher vom Volke erworben, auf spätere Zeiten als heiliges Erbteil an die Enkel vermacht werden und auf diesem Boden eine gleiche Gesinnung fortgepflanzt werden kann.» 1833 wurde eine Vorbereitungsgesellschaft ins Leben gerufen, die Aktien ausgab, um die Mittel für 
Projektstudien zu erhalten. Bei einem so großen Werk sind viele Projekte möglich, vom zaghaftesten und billigsten, der Eindämmung und Gradlegung der Aare im angestammten Lauf von Aarberg nach Büren, bis zu Sonderlösungen, wie der Ableitung der sehr viel Geschiebe führenden Saane durch das Biberntal in den Murtensee. Zur Ausführung kam das Projekt des 1840 berufenen bündnerischen Oberingenieurs La Nicca, welches die Ableitung der Aare von Aarberg über Hagneck in den Bielersee vorsah.

Viele und heftige Kämpfe waren vonnöten, bis dieses Projekt durchdrang, besonders da der General Ulrich Ochsenbein, Oberkommandant des zweiten Freischarenzuges, Nationalrat, Bundesrat bis 1854 , ein Jugendfreund von J. R. Schneider, mit einem Gegenprojekt auf den Plan trat. Erst 1867 beschloß die Bundesversammlung, einen Beitrag von 5 Millionen Franken auszurichten. Am 16. August 1878 floß zum ersten Male Aarewasser durch den Hagneckdurchstich in den Bielersee. Da der Kanal nur teilweise ausgehoben wurde, hatte die Aare noch ca. zwei Millionen Kubikmeter auszuschwemmen. 1891 konnte das gesamte Werk von den eidgenössischen Behörden abgenommen werden. Die Schlußabrechnung ergab einen Kostenbetrag von 143/4 Millionen Franken.

Die große Korrektion hat die Ebenen am Jurafuß grundlegend verändert. Die Aare fließt heute in einem von Dämmen eingefaßten Kanal ohne Waldstreifen. Unterhalb des Bielersees wurde bei Meinisberg eine große Schleife durchschnitten. Die alte Aare zwischen Aarberg und Büren führt nur noch $1 \mathrm{~m}^{3} / \mathrm{sek}$ Wasser. Der begleitende Auenwald wandelt sich langsam in einen überschwemmungsfreien Waldtyp mit ganz anderem Baumbestand. Die Altläufe sind verlandet. Im Großen Moos ist der Grundwasserspiegel gesunken. Durch Kanäle wurde das ganze Gebiet melioriert, danach hat es in Kultur genommen werden können. Vorbildlich ist dabei die große Staatsdomäne der Strafanstalt Witzwil vorgegangen. In den Ebenen der Orbe und der Broye oberhalb der Seen sind Gemüse- und Tabakkulturen entstanden. - Doch auch bei diesem groBen Werk hat sich gezeigt, daß der erste so überaus segensreiche Erfolg der Entsumpfung weiter Gebiete mit der Zeit teilweise wieder in Frage gestellt wird. Durch die Entwässerung hat sich in den Randgebieten der Seen der Boden von 1880 bis 1960 um rund $1 \mathrm{~m}$ gesetzt, und dieser Vorgang hält, wenn auch stark verlangsamt, an, so da $\beta$ in den nächsten 100 Jahren mit einer weitern Setzung um $50 \mathrm{~cm}$ zu rechnen ist. Heute schon werden besonders bei Winterhochwasser über $30 \mathrm{~km}^{2}$ Gelände überschwemmt und weitere Gebiete durchwässert; in der Zukunft ist mit $60 \mathrm{~km}^{2}$ Überschwemmungsgebiet zu rechnen.
So hat sich eine zweite Juragewässerkorrektion aufgedrängt; deren Arbeiten sind heute im Gang. Durch Erweitern der Kanäle der Broye und der Zihl werden die drei Seen besser untereinander verbunden. Der Wasserausgleich wird so rascher vonstatten gehen. Vor allem aber wird der Ausbau des Nidau-Büren-Kanals und daran anschließend der Aare bis unterhalb der Emmenmündung die Abflußverhältnisse vom Bielersee her verbessern. Die Kraftwerkbauten von Flumenthal unterhalb der Emmemündung und von Neubannwil oberhalb Aarwangens sind heftig bekämpft worden - ein Zeichen dafür, wie sehr weite Kreise sich heute für die Erhaltung möglichst wenig veränderter Flußstrecken einsetzen; wird doch befürchtet, daß mit diesen beiden Werken ein weiterer Schritt für die Schiffbarmachung der Aare und damit für das transhelvetische Schiffahrtsprojekt unternommen werde. Der Bericht des Bundesrates vom 11. Mai 1965 kommt allerdings für die Hochrhein- und Aareschiffahrt zu einem negativen Ergebnis.

Probleme der Flußauengestaltung sind zunehmend zu aktuellen politischen Problemen geworden, wie auch die sehr gute Annahme des Wasserrechtsartikels durch das Bernervolk zeigt, der in Form des fakultativen Referendums das Mitspracherecht des Stimmbürgers bei Wasserrechtsverleihungen in sich schließt.

Die Regulierung durch die drei Jurarandseen macht sich aareabwärts bis zum Rhein geltend. Die Hochwasser werden verringert, zumal der Seeabfluß auch auf Emmehochwasser abgestimmt werden kann; andererseits wird aus den als Speicher bewirtschafteten Seen für die Laufwerke in Trockenzeiten zusätzliches Wasser abgegeben.

Die ausgleichende Wirkung macht sich ganz allgemein beim Ausfluß aller Speicher- und natürlicher Seen gelten, besonders wenn diese noch regulierbar sind. So ist das Verhältnis von maximaler zu minimaler Wasserführung am Rhein oberhalb des Bodensees $65: 1$, bei dessen Ausfluß noch $8: 1$. Im Aaretal unterhalb Innertkirchen hat sich der Winterwasserstand seit der Inbetriebnahme der Oberhasliwerke wesentlich erhöht; er zeigt die typischen Belastungsschwankungen der Elektrizitätswerke. Von $4-5 \mathrm{~m}^{3} / \mathrm{s}$ im Dezember 1924 vor dem Bau stieg der Abfluß auf 9-31 m³ im Januar 1953. Durch das Becken von Rossens an der Saane konnten im Januar $195454000000 \mathrm{~m}^{3}$ zurückgehalten werden, so daß der Hochwasserstand des Bielersees um $30 \mathrm{~cm}$ vermindert wurde. Durch die Speicherwerke des Rheingebiets wird der Abfluß bei Basel in den 6 Wintermonaten um rund $100 \mathrm{~m}^{3} / \mathrm{s}$, bei Vollausbau um rund $145 \mathrm{~m}^{3} / \mathrm{s}$ erhöht.

Die Regulierung der Seen und die Speicherwerke wirken sich auf die Wasserführung der Flüsse wie eine Klimaänderung aus; sie hätten auch ohne Flußkorrektionen eine Veränderung der Auenwäl- 
der zur Folge, da die Hochwasser vermindert werden.

Mit der Rhone-, Rhein- und Juragewässerkorrektion sind nur drei ganz große Unternehmungen besprochen worden. $\mathrm{Zu}$ ihnen gesellt sich eine sehr große Zahl kleinerer, die sich über die ganze Schweiz von den Alpen über das Mittelland bis in den Jura erstrecken. Wie tiefgreifend an einzelnen Stellen der Eingriff in die Auenwälder war, zeigt der Plan eines Teiles (Fig. 1) der Aarekorrektion zwischen Thun und Bern unterhalb der Zulg- und der ehemaligen Kandermündung, die zwischen 1871 und 1873 ausgeführt wurde.

A. von Salis, schweizerischer Oberbauinspektor, erwähnte 1883 in einer Schrift für die Schweizerische Landesausstellung des gleichen Jahres als vom Bund subventionierte Korrektionen jene der Aare im Haslital, die der Melchaa und Sarner $\mathrm{Aa}$ in Obwalden, die der Aare von Böttstein bis zum Rhein im Aargau, dann die Unternehmungen an der Thur, Töß, Glatt, Limmat und Sihl, an der Murg im Kanton Thurgau, an den Binnengewässern bei Werdenberg, die Rheinkorrektion im Domleschg, die Korrektion des Davoser Landwassers und die Korrektion des Tessinflusses.

Seit 1883 sind noch andere Korrektionen dazugekommen. Damit sind in vielen Talböden die gewundenen und reich verästelten Flußläufe und die natürlichen Ufer verschwunden. Oft hat man bei der Korrektion auch die Bäume und Gebüsche beseitigt, welche die Gewässer einst begleiteten.

Die Notwendigkeit der meisten dieser tief ins Landschaftsbild eingreifenden Korrektionen erscheint unbestritten. Doch haften namentlich den früheren Werken zu sehr Mängel reiner Reißbrettarbeit an Mit Gebüsch- und Baumpflanzungen kann manche harte Linie gebrochen werden. Bei der Ufer-, Flußund Bachbett-Gestaltung muß auf die Lebensbedingungen von Tieren und Pflanzen so viel Rücksicht genommen werden, daß Fluß und Bach für beide ein harmonisches Milieu darbieten und nicht nur tote Abflußrinnen verkörpern. Denn eine Gewässerkorrektion ist nicht nur ein hydraulisches Problem, sie bedeutet immer auch einen Eingriff in die Landschaft und muß im Rahmen des größeren Ganzen gesehen und gelöst werden.

\section{Die Wasserkraftnutzung}

Schon früh begann der Mensch auch die Kräfte des fließenden Wassers zu nutzen. Mit den geringen technischen Hilfsmitteln, die ihm während des Mittelalters und bis ins 19. Jahrhundert zur Verfügung standen, konnte er noch nicht daran denken, die Energie großer Flüsse ganz auszunutzen. Er richtete an ihren Ufern vor allem Kleinbetriebe ein, wie Getreide-, Öl- und Gipsmühlen, Fruchtpressen, Hirse- und Knochenstampfen, Sägen, Walken, Schmieden, Schleifereien und mechanische Werkstätten. Die Wassernutzung erfolgte mit Hilfe primitiver Wasserräder, die ganz aus Holz bestanden und vom Mühlenmacher handwerklich errichtet wurden. Am günstigsten waren die Voraussetzungen an Seeausflüssen mit ausgeglichener Wasserführung.

Im offenen Fluß wurde die Energie auf Schiffsmühlen gewonnen, so zum Beispiel bei Brugg in der Aare, bei Turgi in der Limmat und bei Eglisau im Rhein. Die Eingriffe in die Flußauen und ins Landschaftsbild waren noch sehr bescheiden, denn die meisten Kleinbetriebe nützten die Energie nur von Bächen aus. Immerhin wurden schon früh Grundwuhren oder Streichwehre erstellt, wie die Schwelle in der Matte der Stadt Bern, die schon vor dem 14. Jahrhundert, eventuell sogar vor 1191 , bestand und an der ein kleiner Teil des Flußwassers in einen Kanal abgeleitet wurde.

Zur Mitte des 19. Jahrhunderts begann eine rasche industrielle Entwicklung. Neben dem Kleingewerbe entstanden immer mehr Fabrikbetriebe mit erhöhtem Energiebedarf. In dieser Zeit wurden auch die ersten leistungsfähigen Turbinen gebaut; sie verdrängten die durch einen schlechten Wirkungsgrad unwirtschaftlichen Wasserräder.

Die älteste in einen Strom gestellte Turbinenanlage verdankt man dem Schaffhauser Großindustriellen Moser; er erbaute sie 1863-1866, wobei durch Drahtseiltransmissionen 560 PS über $650 \mathrm{~m}$ geleitet wurden. Mit den mechanischen (teils pneumatischen) Übertragungen blieben die Fabriken aber weiterhin ans Wasser gebunden, denn Distanzen von über $700-800 \mathrm{~m}$ ließen sich nicht überwinden. So entstanden im Auengebiet an einem Fabrikkanal die großen kahlen Gebäude mit den vielen schmucklosen Fenstern. Oft wurden in der Nähe auch Arbeitersiedlungen mit Mietskasernen oder kleinen Einfamilienhäusern gebaut, in deren Nähe im heckenumgebenen großen Park die Villa des Fabrikanten lag.

Gegen Ende des 19. Jahrhunderts begann die stürmische Entwicklung der Elektrizitätswirtschaft. Sie wirkte sich auf die Flußauen in zweifacher Hinsicht aus. Einerseits wurde der Ferntransport von Energie möglich. Zunächst handelte es sich um tastende Versuche der Energieübertragung für den Eigenbedarf. 1880 konnten in Frankreich 35 PS über $5 \mathrm{~km}, 1886$ zwischen Kriegstetten und Solothurn 50 PS über $8 \mathrm{~km}$ vermittelt werden. 1891 gelang anläßlich einer großen Industrie-Ausstellung die Energie-Übertragung von Lauffen am Neckar nach Frankfurt a. M. über $170 \mathrm{~km}$. Von diesem Zeitpunkt an war es möglich, Industrieanlagen vom Standort am Wasser zu lösen. Gute Verkehrslage, die Nähe des Absatzgebietes und von großen Siedlungen gewannen nun ausschlaggebende Bedeutung. Die Industrie suchte indessen günstiges Bauland, 
und sie fand es oft im neuerschlossenen, durch Dämme geschützten Gebiet der Flußniederungen.

Auf der andern Seite begann mit der aufblühenden Elektrizitätswirtschaft die Zeit der ganz großen Eingriffe in das Flußauengebiet. Da sich elektrische Energie nicht nur fernleiten, sondern auch unbeschränkt verteilen läßt, konnte die Energieproduktion für eine Vielzahl von Konsumenten zusammengefaßt werden, was den Bau großer Flußkraftwerke wirtschaftlich gestaltete. Die ersten Anlagen gehörten überwiegend privaten Unternehmungen, ein kleiner Teil von ihnen Stadtgemeinden. Das erste kantonale Werk baute Freiburg.

Die Wasserrechte sind von Kanton zu Kanton verschieden. Das Hoheitsrecht über die Gewässer besitzt meist der Kanton. In Graubünden und im Wallis (mit Ausnahme der Rhone) sind die Gemeinden zuständig, in Schwyz die Bezirke, in Uri mit Ausnahme der Reuß und einiger Zuflüsse die Korporationen; im Kanton Glarus haben die Uferanstößer besondere Rechte. Die vielfältigen Probleme, die über die Einzelinteressen der Kantone hinausgehen, Kraftwerkanlagen, die mehrere Kantone berühren oder sich an der Landesgrenze befinden, Kraftübertragungsanlagen, der Energieexport usw. haben der Lösung im bundesstaatlichen Rahmen gerufen.

So ist 1908 mit Art. 24bis der Bundesverfassung die Grundlage für eine eidgenössische Energiepolitik geschaffen worden: «Die Nutzbarmachung der Wasserkräfte steht unter der Oberaufsicht des Bundes».

Beim fortschreitenden Ausbau der Elektrizitätswirtschaft zeigte es sich, daß die Laufwerke an den groBen Mittellandflüssen, die sich durch ungleiche Wasserführung und Winterniederwasser auszeichnen, durch Speicherwerke in den Alpen ergänzt werden mußten. So wurden 1908 das Löntschwerk mit dem Speicher des Klöntalersees (Speichervermögen 45 Mio. $\mathrm{m}^{3}$ ) und das Laufwerk Beznau an der Aare elektrisch gekoppelt. Es ist dies ein treffliches Beispiel dafür, wie der Kultureingriff in die Flußauen aus wirtschaftlichen Überlegungen auch zu Kultureingriffen im Quellgebiet der Flüsse führen kann.

Der Ausbau der Wasserkräfte geht heute seinem Ende entgegen. Mit kleinen, unabhängigen Werken an besonders günstig gelegenen Stellen der Mittellandflüsse hat man begonnen. Der Bau des Kraftwerkes Arosa in $1800 \mathrm{~m}$ Höhe wurde 1898 als etwas Besonderes vermerkt. Seither erstellte man Speicherwerke in immer größeren Höhen, bis an den Rand der Gletscher. Sie entzogen vielen Alpenbächen und kleinen Flußläufen so viel Wasser, daß, wo nicht Pflichtwassermengen vorgeschrieben sind, in ihrem Bett zuweilen nur noch bei Regen und während der Schneeschmelze etwas fließt. Dadurch ist auch die Vegetation in den vielen
Miniaturauenwäldchen der Alpenflachstrecken grundlegend verändert worden. Die ausgleichende Wirkung der Speicherwerke auf die Wasserführung, die sich bis ins Mittelland geltend macht und einer Klimaveränderung gleichkommt, haben wir andererseits schon erwähnt. Im Mittelland reiht sich heute an vielen Flüssen Kraftwerk an Kraftwerk; die Gewässer werden dadurch in treppenartig übereinander angeordnete Teilstrecken zerlegt, in denen das Wasser nur noch träge fließt. Oft ist neben dem alten Flußlauf ein dammbewehrter Ober- und Unterwasserkanal angelegt worden, so $\mathrm{da} \beta \mathrm{im}$ alten Bett bei Mittel- und Niederwasser nur noch ein kleines Rinnsal fließt und die Grundwasserverhältnisse in den angrenzenden Grundstücken verändert worden sind. Immer mehr sind die frei fließenden Flüsse gebändigt, zwischen Dämme gezwängt und dadurch die alten Auenwälder entscheidend beeinflußt worden. Die meisten sind in Umwandlung begriffen, wenn sie nicht schon durch Kanal- und Dammbauten vernichtet worden sind. Die Kulturflächen reichen ungefährdet bis an die Flußdämme. Indirekte Auswirkungen der intensiven Wasserkraftnutzung sind die Energieübertragungsanlagen, die nicht nur die verschiedenen Landesteile miteinander verbinden, sondern über alle Landesgrenzen hinausreichen, so daß die Schweiz mit den Nachbarstaaten ein europäisches Verbundgebiet bildet. In neuester Zeit sind die Flußauen durch den großen Wasserbedarf der Atomkraftwerke zu Standorten der modernsten Energieproduktion geworden. Das Atomkraftwerk Beznau-Döttingen wird in einem frühern Schachenwaldgebiet der Aare erstellt, und jenes von Lucens liegt im Talboden der Broye. Auch viele Strecken des Nationalstraßennetzes kommen in die ebenen und oft noch wenig überbauten ehemaligen Flußauen zu liegen.

\section{Die Entwicklung der Flußlandschaft des Aarequer- tales Wildegg-Brugg}

Am Beispiel des Aarequertales Wildegg-Brugg soll die Entwicklung einer Flußauenlandschaft nochmals im einzelnen dargestellt werden.

Von Wildegg bis zur Habsburg quert die Aare den Faltenjura; bis Brugg folgt sie dem Südrand des Tafeljuras. Im Talgrund hat der Fluß zwischen die beidseitigen Jurahänge die großen Schotterflächen der Niederterrasse geschüttet; in sie hat er sich um etwa $30 \mathrm{~m}$ eingetieft. Steilborde begrenzen den tiefsten Talboden, das potentielle Flußauengebiet. Die Aare folgt vornehmlich der rechten Talseite, wohl vor allem deshalb, weil von der linken die größeren Bäche mit mächtigeren Schwemmkegeln münden. So sind die Ternassenflächen der linken Talseite viel geräumiger. 
Beim Einschneiden in die eigenen Schotter verfehlte die Aare bei Brugg die alte Rinne; sie mußte sich hier in enger Schlucht in die Jurakalke neu eintiefen. Der Eingang in diese Felsenge bildet einen Fixpunkt. An ihn blieb die oberhalb hin- und herpendelnde Aare gebunden; und sie verästelte sich gerade oberhalb Brugg stets besonders reich, der Schachenwald erreichte hier bis in die Neuzeit die größte Ausdehnung.

Die Gegend wurde schon früh besiedelt, befinden wir uns doch beim Wassertor des Mittellandes, durch welches sich, wie stein- und bronzezeitliche Funde dies belegen, ein Teil der Einwanderung vollzog. Zur Römerzeit diente der Engpaß von Brugg als einer der wenigen festen Aareübergänge. Bis zum Ende des 19. Jahrhunderts befand sich die nächste Brücke flußaufwärts in Aarau.

Die Besiedlung beschränkte sich auf die Terrassenflächen, vorzüglich die größeren der linken Talseite. Auch die Straßen hielten sich an die Terrassen. Der alluviale Talboden darunter war mit seinem fruchtbaren Schwemmland zwar als Ackerland begehrt, aber häufigen Überschwemmungen ausgesetzt, und diese waren oft mit Laufänderungen des Flusses verknüpft, bei denen Kulturland weggerissen wurde. Siedlungen fehlten diesem gefährdeten Gebiet.

In diesem Talboden wurde im 17. Jahrhundert die Schwefeltherme von Schinznach entdeckt. Der älteste Bericht darüber geht auf das Jahr 1654 zurück, als der Berner Rat eine Untersuchung der Verhältnisse anordnete. Der Quellenaustritt lag damals auf einer Kiesbank am linken Ufer im Bann der Gemeinde Schinznach. So war man gezwungen, zum Ausbau der Quelle für den Badebetrieb Gebäude mitten in das Flußauengebiet zu stellen. Die Geschichte des Bades ist deshalb mit den Veränderungen der Flußauenlandschaft eng verknüpft.

Aus der Zeit um 1660 besitzen wir eine Aufnahme des Eigenamtes durch den hervorragenden Kartographen Conrad Gyger. Darauf ist die reichverästelte Aare detailliert dargestellt. Weit weg vom Fluß, auf den erhöhten Terrassen, befinden sich die Siedlungen. Keine einzige Straße quert das Tal. Ein schwarzes Viereck mitten im Schachen kann als Standort des Bades gedeutet werden.

1660 erwarb ein Berner Patrizier die Konzession zur Nutzung der Quelle. Er beanspruchte dafür Schachenland, das bisher die Schinznacher nutzten und für das sie jährlich der Regierung zinsen mußten, weil «die Schachen und Riesgründ der Hohen Obrigkeit zustehen». Diese stellte ausdrücklich fest, «daß das Holzen und Schwenden in den Schachen gänzlich verboten sein solle, damit die Aar desto minder Gewalt an anderm fruchtbarem Erdreiche schaden zuzufügen, gewinne, und auch für Notfälle und zum Schwenden der Aare Wellen (Holzbürden) daringefunden werden mögen.» Der «Be- schreibung dez köstlichen warme Gesundbads, Bey Schintznacht, an der Aren-Fluß ohnfern der Statt Brug in dem Aergaw, in der Mächtigen $\mathrm{H}$. von Bern Landschafft gelegen» des jungen Zürcher Arztes Hans Jakob Ziegler vom Jahr 1663 sind 2 Kupferstichansichten beigegeben. Darauf sind zwei Gasthäuser, eine Scheune und zwei kleinere Gebäude zu sehen, ganz in der Nähe der Aare. Aber schon im Dezember 1670 wurden die Quelle durch ein Hochwasser verschüttet und die Gebäude zerstört. Dabei wechselte die Aare ihren Lauf und wich nach Westen aus. Als 1686/87 wieder ernsthaft nach der Quelle gesucht wurde, fand man sie auf einer Insel in der Nähe des rechten Ufers. Dieser Laufwechsel hat zu fortwährenden Verwechslungen Anlaß gegeben. Denn nun wurden die Gebäude auf dem Gebiet der Gemeinde Birrenlauf erstellt, die Quelle hieß aber weiterhin Bad Schinznach. Das führte dazu, daß 1937 die Gemeinde Birrenlauf ihren Namen in Schinznach-Bad abänderte und die alte Gemeinde Schinznach nun Schinznach-Dorf genannt werden mußte - ein hübsches Beispiel einer Namensänderung, die durch einen Fluß verursacht wurde.

Der Standort der Quelle mitten im Flußauengebiet zwang zu fortwährenden Eingriffen. Für die Neufassung wurde von den Bernern als Fachmann der Basler Ingenieur G. F. Meyer beigezogen, der 1692 eine Karte der Aare im Bereich der Quelle erstellte und Schutzbauten vorschlug. Diese sollten weit über den Quellbereich hinausreichen, da nur so ein ausreichender Erfolg zu erzielen sei. Aber die ausgedehnten kostspieligen Bauten wurden nie ausgeführt; man beschränkte sich auf die Schüttung eines Dammes, der zur Quellinsel führte, und erst 1757 wurde der östliche Flußarm, der die Insel von den Gebäuden des Bades trennte, trockengelegt. Die Schutzbauten konnten nicht verhindern, daß das Bad noch mehrmals unter Überschwemmungen zu leiden hatte, so 1764, 1800, 1830 und 1852.

Ebenso wie das Bad und seine Gebäude war alles Acker- und Weideland, das in der Flußauenniederung lag, gefährdet. In den Urkunden der Stadt Brugg und der Burg Wildegg ist davon allerdings nur dann die Rede, wenn durch Veränderungen des Besitzstandes Rechtshändel entstanden. Etliche Jahre vor 1600 hatte die Aare Holzland bei Holderbank weggespült, später aber an der gleichen Stelle wieder aufgeschüttet. Die Holderbanker beanspruchten das wieder neu nutzbare Schachenland auf Grund eines Lehensbriefes vom Jahr 1460, wurden aber von den Effingern eingeklagt. Im Urteil wurde das Grundeigentum an diesem Schachen den Effingern bestätigt, hingegen den Bauern von Holderbank die Nutzung der Weide im Schachenwald zugesprochen. 1541 verklagte eine Gemeinde des Eigenamtes die Brugger, daß durch die Wuhren bei der Brugger Schiffsmühle die Aare ans Gegenufer 
gedrängt werde und Ufereinbrüche verursache. 1725 wurde aus Villnachern berichtet, daß 42 Jucharten, die sogenannten Augüter, "vor etlichen Jahren durch die Aare hinweggeflößt worden seien.» Dieses Land mußte im Gemeinwerk wieder urbarisiert werden; der «ober Eggen» wurde dabei unausgestockt gelassen, um das übrige Land zu schützen. Auf der urbarisierten Fläche wollte man «kürbsen, köhl, kraut und dergleichen ansäijen.» Die verwickelten Rechts- und Besitzverhältnisse im ausgehenden Mittelalter waren gründlichen Eingriffen in den Wasserhaushalt hinderlich. Man beschränkte sich auf passive Schutzmaßnahmen, Ufersicherungen an besonders gefährdeten Stellen und Ausbesserungen von Schäden. $\mathrm{Zu}$ größeren Eingriffen fehlten auch die technischen Mittel.

Im Staatsarchiv Aarau befindet sich ein Bericht aus dem Jahre 1705 an die "gnädigen Herren» in Bern über "Joachim Rychiner von Rubischwyl, daß er sich getraue vermittelst seiner erfundenen maschine die Aaren in ein recht beeth zu bringen.» Von Bern wurde «erkent, Er Rychiner solle by Biberstein die prob machen.» $\mathrm{Da}$ sonst nichts über die Sache bekannt ist, muß angenommen werden, daß die Maschine des Erfinders die Probe nicht bestanden habe.

Nur zögernd wurde das Schachengebiet in Kultur genommen. Gebäude wurden in ihm keine erstellt, und die Straßen wurden über die Terrassenböden geleitet. Namen wie Hasliacker, Buchsenacker, Oberrüte, Manlehen mitten im heutigen Jurahochwald zeigen, wo früher gewirtschaftet wurde.

Mit der Helvetik fand die Herrschaft Berns ein Ende, und der Aargau nahmen sein Schicksal selbst in die Hand. Zunächst waren allerdings so viel Aufgaben zu bewältigen, daß dem Wasserbau nicht die nötige Aufmerksamkeit geschenkt werden konnte. Im Rechenschaftsbericht der Regierung von 1837 hieß es: "Im Wasserbau wurde im allgemeinen nicht viel geleistet, weil mit der im Budget ausgewiesenen kleinen Summe nichts Namhaftes hätte ausgeführt werden können.» Auf der Strecke WildeggBrugg wurden «die Wuhrungen am hohen Bord an der Aare oberhalb Altenburg zum Theil repariert.» 1840 hieß es: «das regelmäßig bei größerem Wasserstand vom Fluß bespülte Schachenland» sei «als Staatseigenthum zu betrachten und zu vindizieren", und 1842 wurde ausdrücklich festgestellt: «Da dem Staat zur Sicherstellung und Unterhaltung der Flußufer bis jetzt keine gesetzliche Pflicht obliegt, so geschieht alles, was er hierin thut, freiwillig ....»; als wichtige Aufgabe wurde die sorgfältige Aufsicht betrachtet, damit der freien Schiffahrt keine Hemmnisse erwüchsen.

Noch 1852 betrugen die kantonalen Ausgaben für den Wasserbau bloß Fr. 317.36. Doch schon 1855 waren es Fr. 18 698.78. Damals wurde auch das Projekt der Juragewässerkorrektion erwähnt, von der man guten Einfluß erhoffte. Um diese Zeit begannen die großen Flußkorrektions-Planungen, für die auch ein Gutachten des Projektverfassers der Juragewässerkorrektion, La Nicca, eingeholt wurde. 1865 wurde mit den Arbeiten bei RupperswilAuenstein begonnen.

Durch diese Flußkorrektion sollte die stark verästelte Aare in einen Kanal gezwungen und das Ausufern durch Dämme verhindert werden. Die Ausführung der Arbeiten bei Rupperswil wurden aber verschleppt, da sie zum Teil im Gemeindewerk durchgeführt wurden und die Arbeiter Landwirtschaft betrieben, wenn sie es für günstig erachteten. Auch stellten sich hydraulische Schwierigkeiten ein. Immer noch lag im neu vorgesehenen Bett eine große Kiesbank; 1871 wollte die Aare bei Rupperswil wieder ausbrechen.

Offensichtlich erachtete man die Korrektion der Aare auf der Strecke Böttstein-Rhein als vordringlich. So wurden die Arbeiten zwischen Wildegg und Brugg nochmals zurückgestellt, trotzdem schon seit 1865 Projekte ausgearbeitet wurden und 1883 fertig vorlagen. Da 1900 um die Konzession für ein Wasserwerk bei Schinznach nachgesucht und später noch andere Projekte ausgearbeitet wurden, beschränkten sich die vom Staat verfügten Eingriffe auf Ufersicherungen und die Erstellung von zwei Straßenbrücken mit den nötigen Zufahrtsdämmen bei Wildegg (1870) und bei Birrenlauf, dem spätern Schinznach-Bad (1915). So blieben zwischen Wildegg und Brugg bis in die Mitte des 20. Jahrhunderts ansehnliche Auenwälder erhalten, vor allem auch der Umikerschachen, wohl eines der schönsten Auenwaldgebiete an der Aare. Die größten Veränderungen im Auenwald verursachte die weitabgelegene Juragewässerkorrektion, durch welche die Überschwemmungen nach Zahl und Größe vermindert wurden. Im Bad Schinznach unmittelbar am Aareufer konnten sich so prächtige Buchen entwickeln, eine Baumart, die keine Überschwemmungen erträgt. Der Umfang der Waldungen entlang der Aare blieb unverändert. Einzig im Zweiten Weltkrieg mußte für den Kulturlandgewinn nach dem Plan Wahlen Schachenwald gerodet werden.

\section{Der Kraftwerkbau}

Alle bisherigen menschlichen Eingriffe im Auenwald, die Rodungen, die Ufersicherungen, der StraBen- und Brückenbau und die Anlage der wenigen Siedlungen, dienten der orstansäßigen Bevölkerung und waren fast ausschließlich von ihr ins Werk gesetzt worden.

Beim Kraftwerkbau nun wurde nicht nur auswärts und ohne Befragung der Einheimischen geplant, sondern es wurde auch über den persönlichen Besitz verfügt. Die Projekte wurden auch nicht für 


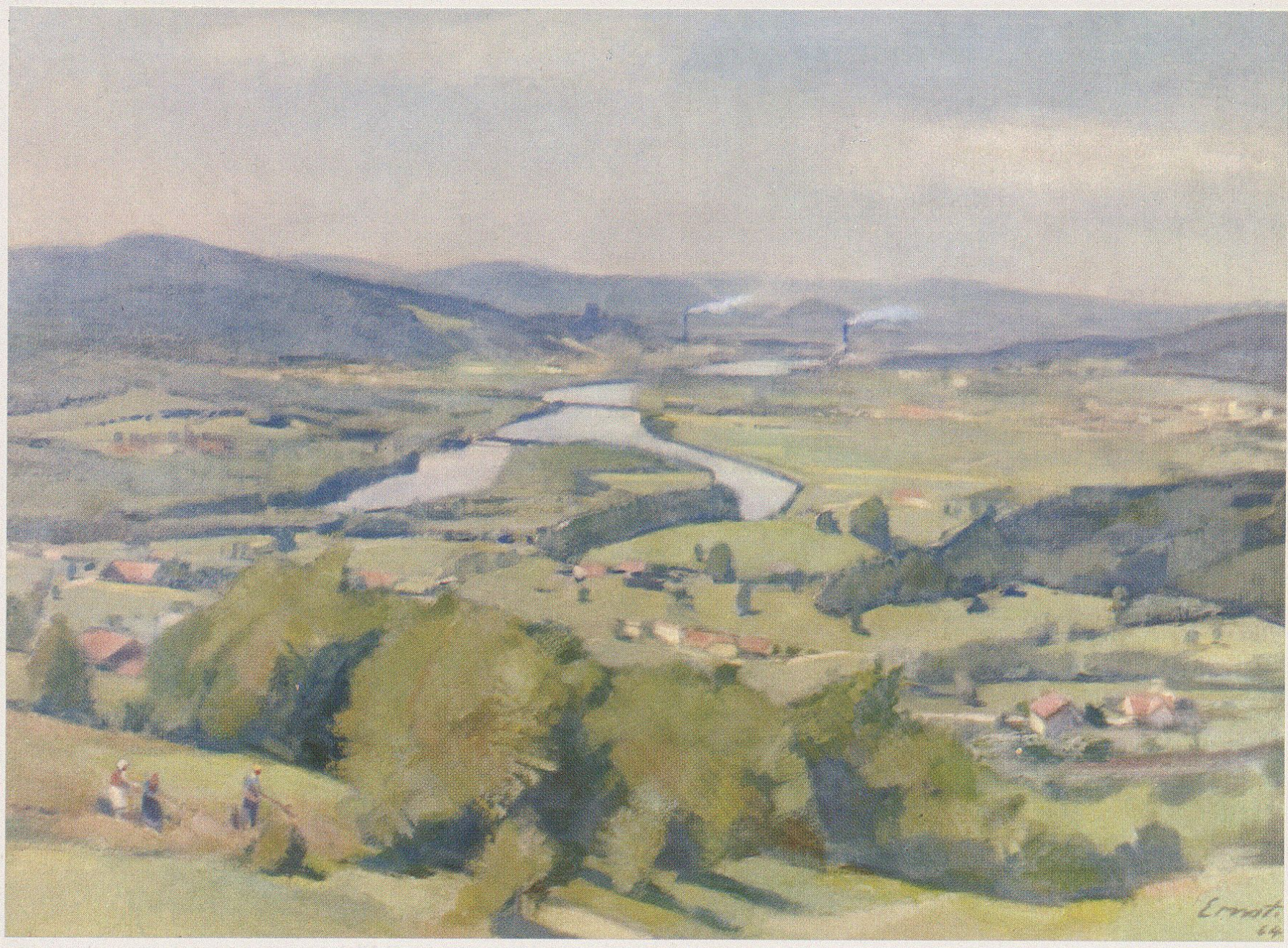

Das Ölbild des Kunstmalers Otto Ernst (1884-1967), Aarau, zeigt die Kulturlandschaft des Aaretales von Vierlinden an der Bözbergstraße (Zürich-Basel), einem bekannten Aussichtspunkt. Von der Aare zweigt beim Stauwehr der Oberwasserkanal ab. Oberhalb sind die breitgestaute Aare und die Brücke von Schinznach-Bad sichtbar. Am Fuß des Bözberges liegt Villnachern, auf der rechten Talseite sind Schinznach-Bad und Holderbank, auf der linken Veltheim sichtbar. Im Hintergrund rauchen die Hochkamine der Zementfabriken von Holderbank und Wildegg, beide im ehemaligen Schachengebiet. Am Taleingang befinden sich die Schlösser Wildegg und Wildenstein, welche mit der (auf dem Bilde nicht sichtbaren) Habsburg im Mittelalter den Durchgang beherrschten. Bei klarem Wetter sind am Horizont die Alpen zu sehen. (Das Bild verdanken wir den NOK Baden.) 
die Bedürfnisse der betroffenen Gemeinden erstellt, sondern die Werke sollten Energie für die Industrie oder für den Export erzeugen. Die Geschichte der Planung von 1900 bis 1948 zeigt, wie für die gleiche Flußstrecke ganz verschiedenartige Projekte erstellt werden können.

1912 war ein Oberwasserkanal von Wildegg bis Villnachern mit anschließendem Unterwasserkanal bis Altenburg-Brugg vorgesehen, der das Aarebett des Wassers beraubt hätte. Der Erste Weltkrieg verzögerte die Konzessionierung. Ein nächstes Projekt sah an Stelle des Kanals einen Stausee mit einer Staumauer in Brugg oder Umiken vor. Dadurch wären rund $3 \frac{1}{2} \mathrm{~km}^{2}$ Kulturland, mit dem Schachengebiet zusammen über $4 \mathrm{~km}^{2}$, unter Wasser gesetzt worden, und das Bad Schinznach wäre hinter Schutzdämmen von 7 bis $10 \mathrm{~m}$ Höhe zu liegen gekommen.

Gegen das Stauseeprojekt erhob sich heftiger Protest, einmal von der Direktion des Bades Schinznach, die ein Gutachten von Prof. Alb. Heim erstellen ließ, dann aber auch seitens einer Gruppe von Bruggern und Vertretern aus den betroffenen Dörfern, die ein Aktionskomitee bildeten.

Der Protest richtete sich einzig gegen den Stausee, nicht gegen das Kanalprojekt, von dem Albert Heim sagte: "Der offene linksufrige Kanal ohne Stausee bringt für das Bad Schinznach keine Gefahren, ändert nichts am Grundwasser . . . Die Schwächung des jetzigen Aarelaufs von Holderbank bis Altenburg... ist zu bedauern, bedeutet aber in keiner Richtung einen wirklichen Schaden, eher führt sie zur Mehrung und Sicherung des Kulturlandes im Talboden. Die Uferpflanzen und wir Menschen werden uns an die verkleinerte Aare bald gewöhnen. Die Störung im landschaftlichen Bilde durch den linksseitigen Kanal wird nicht nennenswert sein.» Immerhin meinte auch Albert Heim am Schluß eines Briefes an die Baudirektion des Kantons Aargau, in dem er sich als "alten Eidgenossen» bezeichnete: "Im Besondern bleibe ich der Überzeugung, daß es ein Irrweg war, der die Auffassung schuf, Heimat- und Naturschutz verlange den Stausee und verdamme den Kanal. Das Gegenteil trifft zu! Noch richtiger: Der wahre Heimatschutz verdammt beides!»

Aber keines der beiden Projekte kam zur Ausführung. Denn nach der Krisenzeit verdüsterten sich auch die politischen Verhältnisse, und der Energieexport kam nicht mehr in Frage. Der Zweite Weltkrieg brach aus. Der Energiemangel machte sich geltend. So wurde mitten im Weltkrieg der Bau des Kraftwerkes Rupperswil-Auenstein bewilligt und 1941 mit den Arbeiten begonnen. Damit rïckte der Kraftwerkbau bis wenig oberhalb des Bereichs des Aarequertals, Wildegg-Brugg blieb die einzige noch leicht ausbaufähige Aarestrecke im Aargau.
1946 bewarben sich die Nordostschweizerischen Kraftwerke (NOK) um die Konzession. Bei deren Übertragung lagen zwei Projekte vor. Der Kampi, der entbrannte, drehte sich um das vom Regierungsrat empfohlene Einstufenprojekt der NOK und um ein Zweistufenprojekt, bei dem nur ein ganz kleines Kanalstück vorgesehen war.

Seit 1930, als der Stausee und das Kanalprojekt zur Diskussion standen, hatte sich manches geändert. Im Zweiten Weltkrieg mußten die letzten Landreserven in Kultur genommen werden. Die zunehmende Bevölkerung verlangte aber für Siedlung, Straßen, Sport- und Flugplätze und für die Indlistrie immer mehr Kulturland. Kulturland war eine Mangelware geworden, der bäuerliche Besitz wurde ständig und in bedrohlichem Maße vermindert. Durch den Kraftwerkbau waren immer mehr Flußstrecken ausgenützt worden. Allein im Aargau waren seit 1930 die Kraftwerke Albbrugg-Dogern und Reckingen am Rhein, Klingnau und Rupperswil-Auenstein an der Aare, Wettingen an der Limmat gebaut worden. Die Einsicht, daß auch bei sorgfältiger Planung unersetzliche Landschaftswerte verlorengingen, brach sich immer mehr Bahn. Mußte doch bei jedem Kraftwerkbau das vorher ungehemmt strömende Wasser zwischen Dämme gezwängt werden, in welchen es nur noch träge floß. Für den Schachenwald bedeutete wohl fast jeder Kraftwerkbau den Untergang, weil oft bedeutende Teile gerodet wurden und bei dem, was übrigblieb, durch Veränderung des Grundwassers der Wandel in einen gewöhnlichen Wald erfolgte. Die Aarestrecke Wildegg-Brugg war zudem der letzte noch unverbaute Flußabschnitt der Aare im Aargau und unbestritten mit seinen Jurahöhen und Burgen der schönste.

Bad Schinznach fürchtete, daß durch den Kraftwerkbau seine Quelle geschädigt werden könnte.

Der Kampf der Gegner drehte sich um die Interessen der Landwirtschaft und um die Quelle von Bad Schinznach; er ging aber auch rein ideell um Natur und Heimat. Für den Bewohner einer Landschaft ist jeder Eingriff mit dem Verlust von Altgewohntem verbunden und oft schmerzlich. Da er sich zum Projekt einer Kraftwerkanlage nicht maßgebend äußern kann - die Planung wird von Fremden durchgeführt, und der Entscheid liegt bei der obersten Behörde - hat das Unternehmen selbst den Charakter eines unabwendbaren Schicksalsschlages, den man über sich ergehen lassen muß. Natürlich kann dem entgegengehalten werden, daß die Zeit alle Wunden heilt und der Mensch sich meist überraschend schnell an alles gewöhnen kann, die junge Generation aber von frühern Zuständen ohnehin nichts weiß und kennt. Aber es stellt sich doch für viele die Frage, ob derartige Veränderungen nicht einen Kulturverlust mit sich bringen, der durch den wirtschaftlichen Ge- 

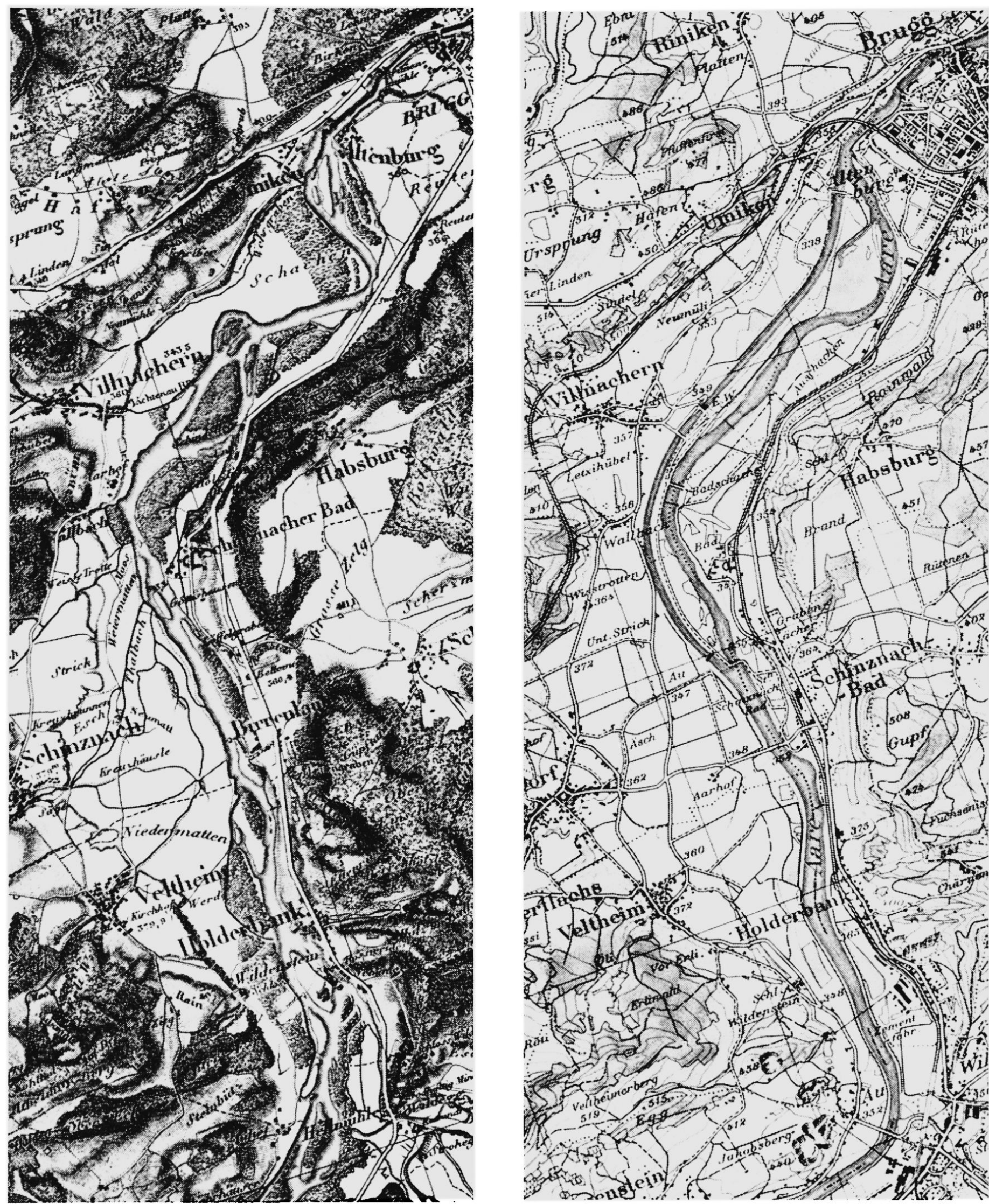

Die Aarelandschaft Wildegg-Brugg 1837 und 1958

Reproduziert mit Bewilligung der Eidg. Landestopographie vom 28. März 1967

Karte von E. H. Michaelis, 1:50 000

Reich verästelte Aare zwischen Auenstein und Holderbank, und unterhalb des Schinznacher Bades mit ausgedehnten Schachenwäldern. In Holderbank, Birrenlauf und Schinznacher Bad Fähren.
Landeskarte 1:50 000

Gestaute Aare, Ober- und Unterwasserkanal. Nur noch Uferwaldreste. Straßen, Fahrwege und vereinzelte Häuser im ehemaligen Schachengebiet, mehrere Brücken. 
winn nicht aufgehoben werden kann. - Eine merkwürdige Diskussion entspann sich. Die Befürworter des Kraftwerkbaues konnten mit Zahlen argumentieren, den finanziellen Vorteil für den Kanton nachweisen, den Energiemangel belegen und die Notwendigkeit für unsern heutigen Kulturstaat begründen. Die Gegner brachten auch Zahlen bei, es ging ihnen aber vor allem um nicht meßbare Gemütswerte, die sich nicht rational begründen lassen. Befürworter und Gegner sprachen verschiedene Sprachen.

Die Abstimmung im Großen Rat führte schließlich 1948, trotz eifriger Propaganda für das Zweistufenprojekt, zur Annahme des Einstufenprojektes. Es wurde in den Jahren 1949 bis 1953 ausgeführt. In den Konzessionsbestimmungen heißt es in Art. 5a: «Sämtliche Anlagen müssen so ausgeführt werden, daß sie das Landschaftsbild möglichst wenig beeinträchtigen. Insbesondere ist der Gestaltung der Umgebung des Bades Schinznach alle Sorgfalt zuzuwenden. Weisungen des Regierungsrates über Natur- und Heimatschutz hat die Konzessionärin auf ihre Kosten nachzukommen.»

Um diese Bestimmung ins rechte Licht zu rücken, müssen wir uns in die Zeit der ersten Kraftwerkbauten zurückversetzen, die auf privater Basis nach vorwiegend wirtschaftlichen Gesichtspunkten erstellt wurden und bei denen man auf die Landschaft wenig Bezug nahm. In der alten Konzession von 1917 hieß es nur: «Ferner ist dabei auf möglichste Schonung der öffentlichen und privaten Interessen Bedacht zu nehmen, insbesondere auf gute architektonische, der Gegend angepaßte Ausgestaltung des Wehres und der Gebäude.» Mit der ausdrücklichen Erwähnung von Natur- und Heimatschutz wurden nunmehr Gesichtspunkte in die Konzession aufgenommen, die von einem neuen Verantwortungsbewußtsein der Landschaft gegenüber Zeugnis ablegen.

So wurde schon bei der Planung des Kraftwerkes auf schonende Eingriffe Rücksicht genommen. Bei der Ausführung, vor allem aber nach Abschluß der technischen Arbeiten, wurde alles getan, um alte Arbeitsplätze, Dämme und Ufer wie die Umgebung der Bauten möglichst naturgemäß wieder anzupflanzen. Das war nur mäglich, weil man bei Baubeginn den Humus abgehoben und gesondert gelagert hatte, so daß mit ihm nach dem Ende der Arbeiten alle kahlen Stellen sorgfältig abgedeckt werden konnten. 15 ha wurden wieder voll aufgeforstet.

Im Kleinen und im Großen hat sich viel geändert. Infolge der Absenkung des Grundwassers wandelt sich der Umikerschachenwald allmählich in einen neuen Waldtypus. In einem Reservat von 7,5 ha Fläche sollen diese Veränderungen studiert werden. Das Baden im offnenen Fluß, wie es früher an verschiedenen Orten üblich war, hat gänzlich aufgehört. Die zunehmende Verschmutzung hat es in den letzten Jahrzehnten wohl in den meisten Mittellandflüssen stark beeinträchtigt. Dafür sind im ehemaligen Schachengebiet Schwimmbäder gebaut worden. Das freie Baden hat sich zum Massenbetrieb auf eng umzäumtem Raum gewandelt.

Das Wasser fließt in den Staugebieten so träge, daß sich hier eine große Schwanenkolonie hat bilden können, die Jahr für Jahr Brutstellen besetzt. Im Winter wird der gestaute Fluß heute von Hunderten einheimischer und nordischer Enten bevölkert; Schwärme von Möven können auf der Aare, aber auch hinter dem Pflug des Bauern gesehen werden. Die Neupflanzungen haben sich gut entwickelt und unterbrechen bereits die geraden Linien der Dämme, die auch dort, wo das Wasser im alten Bett gestaut wurde, das Ufer bilden. So verkörpert der Kraftwerkbau Wildegg-Brugg ein gutes Beispiel eines möglichst schonenden Eingriffes in das Landschaftsbild.

Der Blick von Vierlinden an der Bözbergstraße zeigt sehr anschaulich den großen Wandel: Vom reichverzweigten Flußnetz von einst ist heute nichts mehr zu sehen. Die Tallandschaft ist durch und durch kultiviert. Die Aare ist gebändigt. Bis zum Stauwehr fließt sie zwischen Dämmen, dann legen sich neben das alte Bett die großzügig geschwungenen Bögen des Ober- und Unterwasserkanals. Der frühere Auenwald wird nicht mehr überschwemmt und ist in rascher Umwandlung begriffen.

\section{Die heutige Aufgabe}

"Die Zeit ist kein Sumpf, sie ist ein Strom. Alle Völker nennen sie so und mit Recht. Denn Stillstand ist nirgends, sondern fortwährender Wandel der Dinge und darum Verwandlung von allem.» $\quad H$. Zschokke

In der Entwicklung der Flußauen zur Kulturlandschaft läßt sich eine Folge von Stadien immer kürzerer Dauer erkennen.

Im ersten Stadium beschränkte sich der Mensch auf reine Schutzmaßnahmen, in der prähistorischen Zeit mit primitivsten Mitteln, in der Römerzeit mit beachtlichem technischem Einsatz. Durch das ganze Mittelalter hindurch bis in die Neuzeit wurde vorwiegend örtlich gearbeitet, unzusammenhängend hier und dort das Ufer verstärkt; derart wurden einzelne besonders wertvolle Objekte, Siedlungen, Landparzellen, Straßen und Brücken geschützt.

Im zweiten Stadium wurden die großen Flußkorrektionen und Meliorationen durchgeführt. Die Anfänge reichen ins 18 . Jahrhundert zurück. Ihre große Zeit war vor allem das 19. Jahrhundert. Die reichverzweigten Gewässer zwängte man in begradigte Betten. Der gesicherte Talboden wurde 


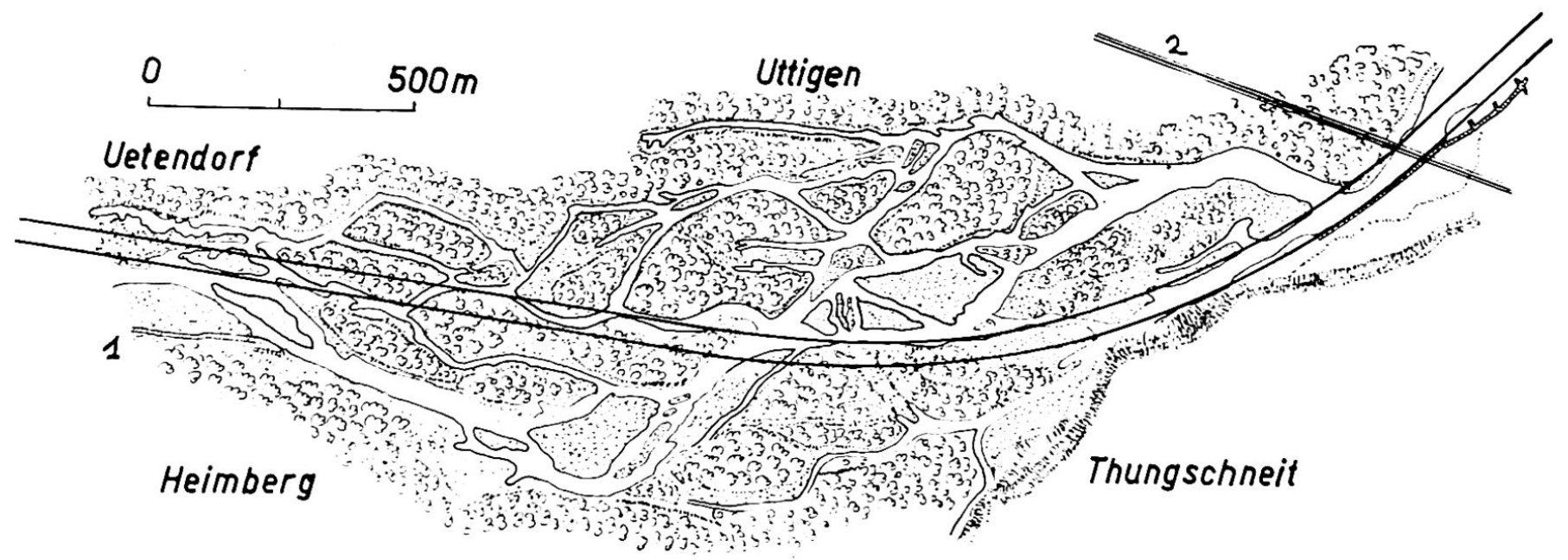

Korrektur der Aare unterhalb Thun. Verästeltes Flußnetz mit projektierter Rinne. 1. Rest der alten Heimbergschwelle; 2. Centralbahn, heute SBB Bern-Thun.

entsumpft und entwässert und konnte in Kultur genommen werden. Die großen Werke konnten nur durch den Staat durchgeführt werden.

Das dritte Stadium ist der Zeitabschnitt der Wasserwirtschaft. Die Initiative ging hier von Privaten aus. Aber immer mehr schaltete sich die öffentliche Hand ein. Die Wassernutzung als Kraftquelle reicht zwar bis ins Mittelalter zurück; die große Entwicklung begann indessen erst am Ende des 19. Jahrhunderts. Sie spiegelt sich in instruktiver Weise in den Titeln der Rechenschaftsberichte des aargauischen Regierungsrates. Sie heißen der Reihe nach: bis 1892 Radrechtskonzession, da bis dahin die Kleinbetriebe, vorweg die Mühlen mit ihren Rädern, die Hautpnutznießer waren, dann bis 1906 Wasserwerke, bis 1915 Wasserrechte und Wassernutzungsrechte und endlich ab 1916 Wasserwirtschaft.

In diesem Stadium sind die Eingriffe in die Flußlandschaft gewinnbringend. Der Staat ist in den konzessionierten Flußstrecken der Unterhaltspflichten enthoben, da er sie dem Konzessionär überbinden kann. Es müssen für diese Wasserbauten keine öffentlichen Mittel mehr eingesetzt werden, vielmehr bilden die Gebühren eine wichtige Einnahmequelle des Staates.

Das vierte Stadium ist das des Gewässerschutzes. Im ehemaligen Gebiet der Auenwälder werden nahezu alle Flußstrecken durch Wasserwerke genutzt. Es konnte mehrmals gezeigt werden, wie sehr die Umwandlung der menschenleeren Naturlandschaft in Kulturlandschaft durch die stetig steigende Bevölkerungszahl bedingt wurde. 1960 konnten in der Schweiz nahezu 51/2 Millionen Einwohner gezählt werden. Schon steigt die "Großstadt Schweiz als schreckende Vision» vor uns auf. Die große Bevölkerung braucht nicht nur Wohnung, Nahrung, Kleidung und Arbeitsstätten, sondern vor allem auch reines und gesundes Wasser. Wir müssen den Übergang von der Wasserwirtschaft zur Wasserpflege finden.

Die Gewässerverschmutzung ist ein erschreckendes Beispiel für die ganz unbeabsichtigten Nebenwirkungen der menschlichen Eingriffe in der $\mathrm{Na}$ tur. Ungewollt wird eine solche Nebenwirkung, die zunächst harmlos erscheint und unbeachtet bleibt, zur Gefahr.

Beim Wasser begann die Verunreinigung mit den Rodungen, welche bei starken Regenfällen die klaren Flüsse zu braunen Fluten werden ließen, aus denen zum Beispiel im Aarequertal Wildegg-Brugg im Durchschnitt $1 \mathrm{~m}$, im Extremfall bis zu $2 \mathrm{~m}$ Auelehm abgelagert wurden. Zu dieser Trübung, welche sich auf Starkregenzeiten beschränkt, kommt in der Neuzeit die Verschmutzung durch den Unrat und die Abfälle der Siedlungsgebiete. Vor allem der Mensch in seiner Überzahl, paradoxerweise die größere Sauberkeit des Menschen, die gesteigerte Hygiene und dazu die Industrie mit ihrem erhöhten Wasserbedarf und ihrer oft schwer abbaubaren Abfallstoffen haben diesen Zustand herbeigeführt. So stehen wir vor «der Notwendigkeit einer zielbewußten Ordnung aller menschlichen Einwirkungen auf das Wasser». Dabei handelt es sich nicht nur um die Beschaffung von sauberem Trinkund Brauchwasser, sondern darüber hinaus um den Schutz ebenso lebensnotwendiger Gemütswerte. Denn so erfrischend und erheiternd klares Flußund Seewasser auf uns wirkt, so unästhetisch, abstoßend, ja deprimierend empfinden wir schmut- 


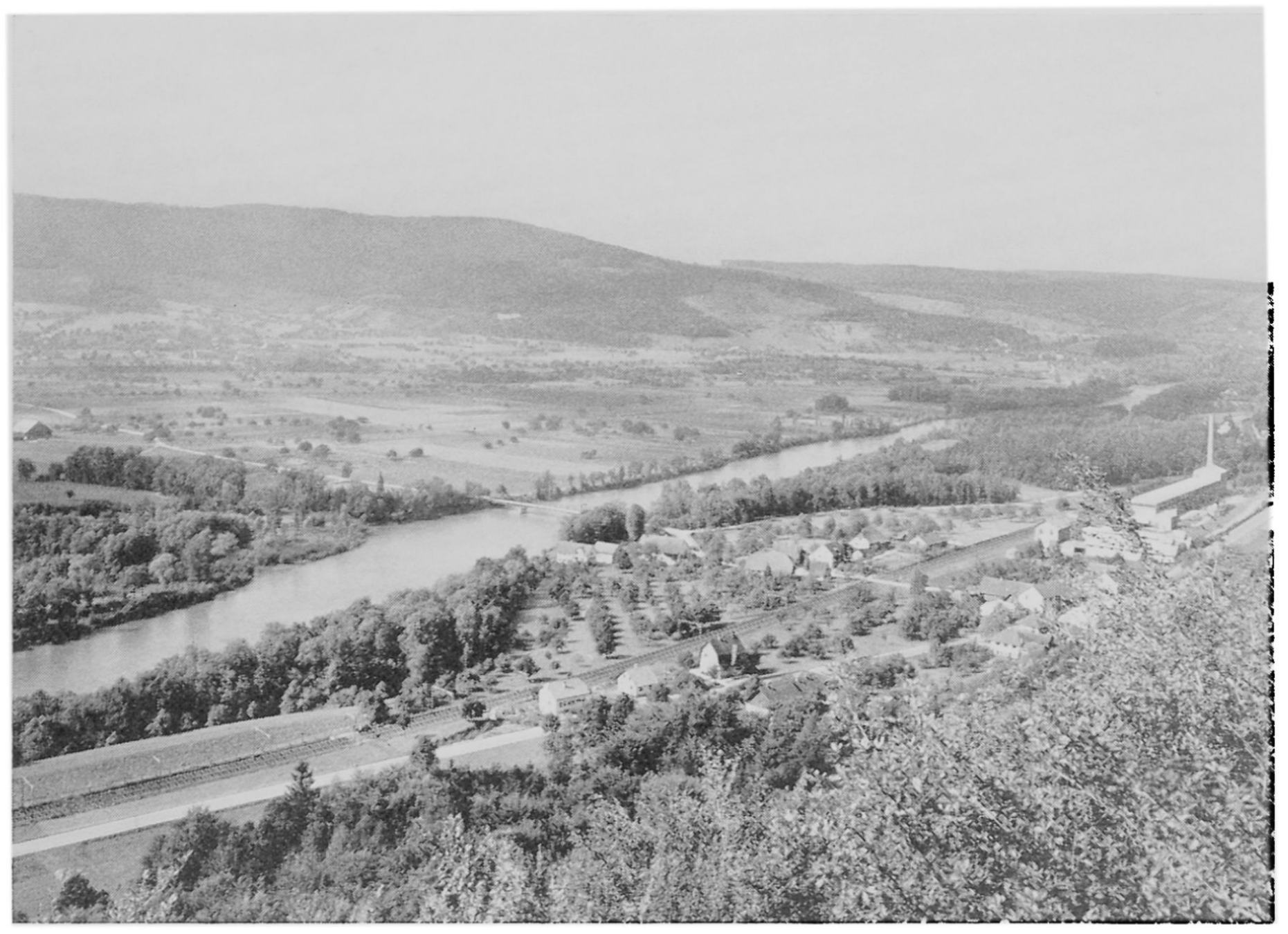

Wandlung der Aarelandschaft bei Schinznach:

Abb. 1 Aufnahme vom 15.9. 1948, vor dem Kraftwerkbau. Vom rechten Hang bei Schinznach-Bad (Punkt 483) aareabwärts mit alter Brücke und Schachenwaldresten.

ziges und unangenehm riechendes Wasser. Gewässerschutz ist eine Aufgabe, die uns alle angeht und uns zwingt, viele alte Sitten und Bräuche zu verlassen. So dürfen wir nicht mehr ungehemmt und wohl einem Urtrieb folgend, alles ins Wasser werfen, was wir nicht mehr brauchen können, so gut wic wir ja auch nicht mehr ungehemmt und triebhaft Blumen pflücken dürfen. Aber über diese elementaren Erziehungsaufgaben hinaus bedeutet der Gewässerschutz eine Rechtsfrage, welche über den privaten und kantonalen Rahmen hinaus einer großräumigen Regelung gerufen hat. So ist Art. 24 quater der Bundesverfassung entstanden: "Der Bund ist befugt, gesetzliche Bestimmungen zum Schutze der ober- und unterirdischen Gewässer gegen Verunreinigungen zu erlassen. Der Vollzug dieser Bestimmungen verbleibt unter der Aufsicht des Bundes den Kantonen.»

Mit dem Schutz der unterirdischen Gewässer erstreckt sich die Aufgabe nicht nur auf das schmale Flußbett, sondern auch auf die breiten Talgründe, die früher vorzüglich von Auenwäldern bestockt waren. Hier, in den Kiesen und Sanden des Untergrundes, befinden sich die großen, aber auch nicht unbeschränkten Wasserreservoirs, die Grundwasserströme, auf die bei der so unheimlich angewachsenen Bevölkerung immer mehr gegriffen werden muß. Das ehemalige Gebiet der Flußauen, seines natürlichen Schutzes beraubt, kultiviert und wciträumig überbaut, muß nun durch Verordnungen und technische Maßnahmen saniert werden.

Das fïnfte Stadium hat erst begonnen und stellt den Zeitabschnitt der allgemeinen Natur- und Landschaftspflege dar. Sie muß sich auf die Erkenntnis stützen, daß nur eine allesumfassende Planung in einem dicht bevölkerten Gebiet die ungewollten schädlichen Nebenwirkungen wirtschaftlich siinvoller Nutzung bannen kann. Als Beispiel sei auf die Waldwirtschaft hingewiesen, wo die restlos :ationale Nutzung durch eine Art Waldacker mit Reihenpflanzung und Kahlschlag zu schweren Schäden geführt hat. Der heutige Förster weiß, daß 


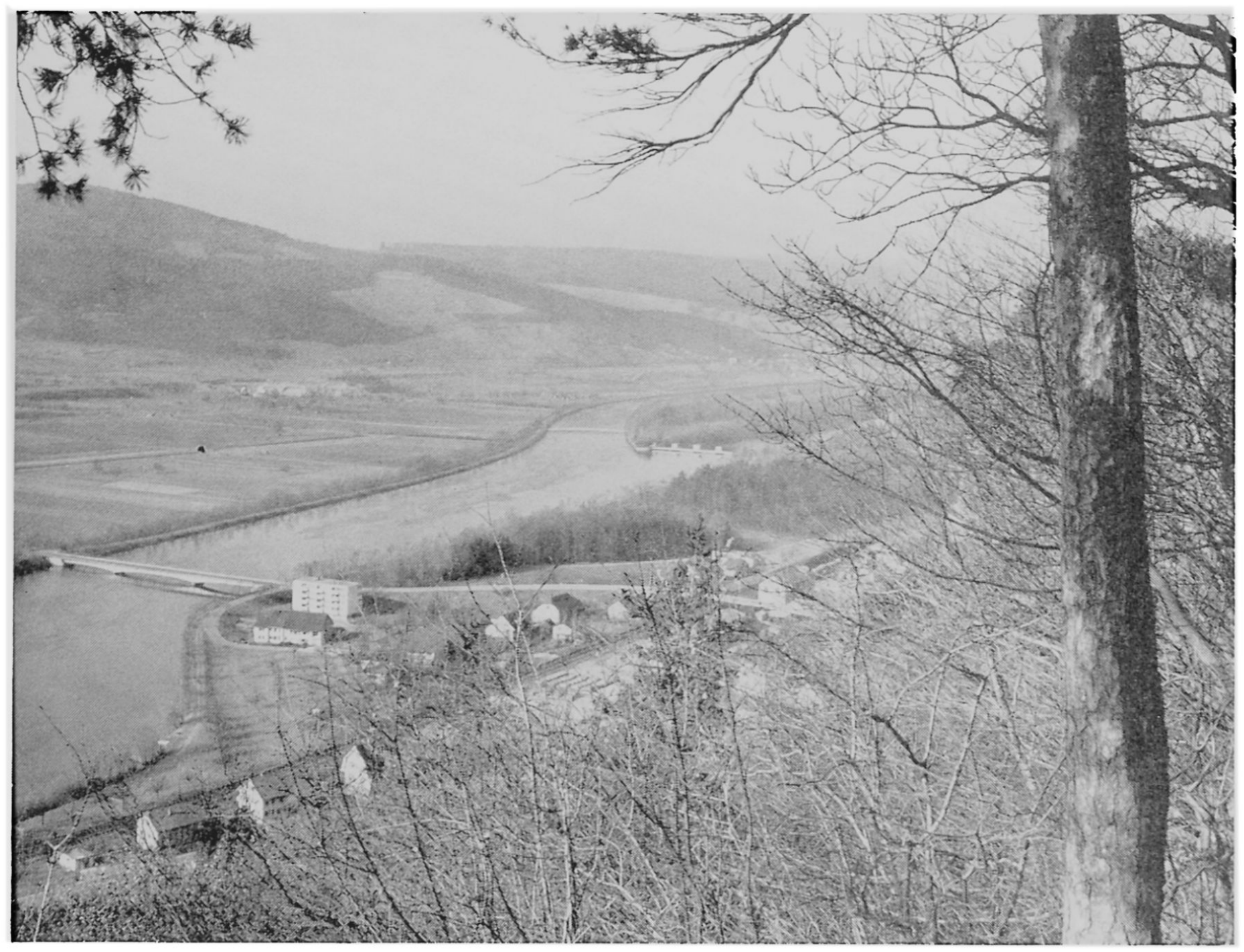

Wandlung der Aarelandschaft von Schinznach:

Abb. 2 Aufnahme vom 31.1.1967, nach dem Kraftwerkbau. Dammbepflanzung mit Bäumen und B̈̈schen, gestaute Aare, Stauwehr und Oberwasserkanal, neue Brücke und Wohnblock im ehemaligen Schachengebiet.

Höchsterträge nur in einem ungleichförmigen Hochwald $\mathrm{zu}$ erreichen sind, in dem möglichst schonend und pflegend geerntet wird. Die Einsicht, daß der Wald mehr als ein Rechenexempel darstellt und in seiner Gesamtheit als ein äußerst subtiler lebendiger Organismus zu behandeln ist, muß auf die ganze Landschaft übertragen werden, von der Wälder und Flußauen nur Teile bilden. Für die ganze Kulturlandschaft ist ein dynamisches Gleichgewicht anzustreben, indem jedes Teilgebiet mit dem andern in Harmonie steht und keines das andere über Gebühr einengt. In der Kulturlandschaft ist der Mensch nicht nur Nutznießer und Gestalter; er bildet auch einen ihrer integralen Teile. Er hat sich in der Landschaft nicht nur zu ernähren, er ist nicht nur Siedler, der Energiequellen ausbeutet; er muß sich in der von ihm gestalteten Landschaft auch wohlfühlen, er muß sich erholen und in ihr gesund leben können.
Der Kulturphilosoph Huizinga hat mitten im Zweiten Weltkrieg in den besetzten Niederlanden be wegte Worte für «die Kulturverluste innerhalb der letzten hundert Jahre» gefunden. Er bezeichnete die Eingriffe des Menschen geradezu als "Untergang der Landschaft". "Das Verschwinden der unberührten Natur ist ein Phänomen, das erst jetzt, um die Mitte des zwanzigsten Jahrhunderts, in seinem ganzen Umfang erkennbar wird ... Wir sprechen hier von Kulturvernichtung, von der Tatsache, daß die Erde für echte Kultur unbrauchbar gemacht wird, während man sie zur Nutzung und Erzeugung einer immer größeren Anzahl nützlicher Produkte bearbeitet... Mit der Verstümmelung einer Landschaft verschwindet viel mehr als ein idyllischer oder romantischer Hintergrund; es geht ein Teil dessen verloren, was den Sinn des Lebens ausmacht.»

Der Kulturverlust, den wir durch Übernutzung der 
Natur verursacht haben, reicht weit in die geschichtliche Vergangenheit zurück. Teilweise war er unvermeidlich, oft wurde er durch Kulturgewinne kompensiert. Denn wenn heute an Stelle eines unverdorbenen Urwaldes eine Stadt in einer intensiv genutzten Landschaft steht, so möchten wir kaum alle Kulturwerte, die sie zu bieten vermag, missen. Der Ruf kann auch im Zeichen der Rousseau-Renaissance nicht einfach heißen: «Zurück Dur Natur.» Unberührte Natur im Vollsinn würde ja den Ausschluß des Menschen bedeuten. Bär und Wolf mußten aus den dichtbevölkerten Gebieten verschwinden. Flußauen mußten ob der Zunahme der Bevölkerung in Kultur genommen werden. Aber die Úbernutzung der Natur mußte den Naturschutzgedanken erzeugen. Er ist, so wie ihn die Besten vertreten, etwas paradox ausgedrückt, ein Schutz der Natur vor dem Menschen, aber für den Menschen. Denn uns und den spätern Generationen soll, soweit das möglich ist, erhalten bleiben, was wir an Eigenartigem, Einmaligem und Schönem übernommen haben. Längst ist der Naturschutzgedanke über den Kreis einiger weniger in breite Volksschichten gedrungen. Aber in die Tat umgesetzt kann er nicht nur durch Erziehung, er muß gesetzlich verankert werden. Die Volksabstimmung vom 27. Mai 1962 hat gezeigt, daß das Gebot der (letzten) Stunde weitherum erkannt wurde. Art. 24 der Bundesverfassung, den wir schon mehrmals zitiert haben, ist um Art. 24sexies (quinquies befaßt sich mit der Atomenergie und dem Strahlenschutz) erweitert worden: "Der Natur- und Heimatschutz ist Sache der Kantone. Der Bund hat in Erfüllung seiner Aufgaben das heimatliche Landschafts- und Ortsbild, geschichtliche Stätten sowie Natur- und Kulturdenkmäler zu schonen und, wo das allgemeine Interesse überwiegt, ungeschmälert zu erhalten. Der Bund kann Bestrebungen des Natur- und Heimatschutzes durch Beiträge unterstützen sowie Naturreservate, geschichtliche Stätten und Kulturdenkmäler von nationaler Bedeutung vertraglich oder auf dem Wege der Enteignung erwerben oder sichern. Er ist befugt, Bestimmungen zum Schutz der Tier- und Pflanzenwelt zu erlassen.»

Von den vielen Elementen der Kulturlandschaft, die geschützt werden müssen, weil die Seltenheitswert bekommen haben, sind hier die Flußauen mit unverdorbenem Schachenwald anzuführen. Sie eignen sich in ganz besonderer Weise als Naturschutzgebiet, nicht nur für wenige Auserwählte, sondern im Gegenteil für alle, die daran Freude haben und sich darin erholen können. So sind denn auch im "Inventar der zu erhaltenden Landschaften und $\mathrm{Na}$ turdenkmäler von nationaler Bedeutung» die Reußlandschaft, die Aarelandschaft Thun-Bern, der Aarelauf Büren-Solothurn und die Altwässer der Aare und der Zihl mitgenannt. Dabei ist nicht zu übersehen, daß keine dieser Landschaften völlig unverdorben und unberührt ist; keine ist eine reine Naturlandschaft im strengen Sinn, denn in allen wirtschaftete schon der Mensch, und das Wasser, das durchfließt, ist verschmutzt. Im Kommentar zur Aarelandschaft Thun-Bern wird ausdrücklich erwähnt: "Wichtiges Grundwassergebiet und Erholungslandschaft der Bewohner von Bern und Thun.»

Wenig vom Menschen beeinflußte Naturlandschaften sind vor weiteren Eingriffen zu schützen. Aber Schutz allein genügt nicht mehr. Künstliche Eingriffe werden in zunehmendem Maße notwendig, damit rasch ideale Bedingungen für bestimmte Lebensgemeinschaften entstehen. Für die Flußauen heißt dies, daß in gewissen Gebieten auch an künstliche Überschwemmung gedacht werden sollte, wenn man die Pflanzen- und Tiergemeinschaften des Auenwaldes erhalten oder wieder neu sich bilden lassen möchte. In solchen Schutzgebieten, mitten in dichtbesiedelten Landschaften, ergibt sich dann das Erstaunliche, daß sich scheue Tiere nirgends besser beobachten lassen als $\mathrm{da}$, wo sie die Menschen als harmlose Naturwesen kennenlernen. Unser Gang durch die Geschichte der Flußauen hat uns gezeigt, daß schon seit langem in der Schweiz produktive Gewässerpolitik betrieben wird. Sie befaßt sich mit dem Gewinn von Kulturland, sie sichert dieses vor Überschwemmungen, sie regelt die Nutzung der Wasserkräfte, sie befaßt sich mit der Flußschiffahrt, sie schützt das Wasser und regelt den Fischfang, sie pflegt und bewahrt die Naturschönheiten.

Viele dieser Aufgaben scheinen rein technisch-wirtschaftlicher Art zu sein und werden oft etwas abschätzig zur Zivilisation gerechnet, der die scheinbar wertvollere und geistig höherstehende Kultur gegenüberstehe. Das ist ein Mißverständnis. Kultur beschränkt sich nicht auf Kunst und Wissenschaft, sie umfaßt alles, was der Mensch durchschauen kann und was sein Geist ersonnen und in die Tat umgesetzt hat. Und so muß auch bei der Nutzung, Gestaltung, Hege und Pflege der Landschaft als der Wohnstätte des Menschen Kultur als ein harmonisches Ganzes angestrebt werden. 


\section{Hauptsächliche Quellen}

1. Aargau: 150 Jahre Kanton Aargau im Lichte der Zahlen. 1803-1953. Herausgegeben vom Reg.-Rat des Kts. Aargau, Aarau 1954.

2. Altere Eidg. Abschiede. Amtl. Sammlung, herausgegeben von G. Meyer von Knonau. Bd. 8 (1778-1798), Zürich 1856.

3. Bachmann, I.: Die Kander im Berner Oberland. Bern 1870.

4. Becker, F.: Das Linthwerk und seine Schöpfer Jahresber. Geogr.-Ethn. Ges. Zürich 1911.

5. Besprechung anbautechnischer Fragen in industriellen Pflanzenwerken im Kt. Wallis. Protokoll 1947.

6. Boner, G.: Die Urkunden des Stadtarchivs Brugg. Aarau 1937.

6. a Burger, H.: Der Wasserhaushalt im Sperbelund Rappengraben von 1915/16 bis 1926/27. Mitt. Schw. Anst. forstl. Versuchswesen XVIII, 1934.

7. Culmann, C.: Bericht an den hohen schweizerischen Bundesrath über die Untersuchung der schweiz. Wildbäche, vorgenommen in den Jahren 1858, 1859, 1860 und 1863. Zürich 1864.

8. Dierauer, J.: Briefwechsel zwischen Joh. Rud. Steinmüller und Hans Konrad Escher von der Linth (1796-1821). Hist. Ver. St. Gallen. XXIII 1889.

9. Eidg. Amt für Wasserwirtschaft. Statistik der Wasserkraftanlagen der Schweiz.

10. Effinger, J. îv.: Chronik der Burg Wildegg. Zürich und Brugg 1907-1911.

11. Escher, H. C.: Etwas über Bergschlipfe, besonders über die im Nolla- und Plessurthal. Leonhards Mineralog. Taschenbuch 1821.

12. Ellenberg, H.: Vegetation Mitteleuropas mit den Alpen. Stuttgart 1963.

12. a Engler, A.: Untersuchungen über den Einfluß des Waldes auf den Stand der Gewässer. Mitt. Schw. Anst. forstl. Versuchswesen 12, 1919.

12. b Frey, A. A. (Schriftleitung): Von der I. zur II. Juragewässerkorrektion. Twann (o. J.).

13. Früh, J.: Geographie der Schweiz. St. Gallen 1930.

14. Gessner, H. und Siegrist, R.: Bodenbildung, Besiedlung und Sukzession der Pflanzengesellschaften auf den Aareterrassen. Mitt. Aarg. Natf. Ges. Heft XVII, 1925.

15. Glarner, P. und Zschokke-Glarner, L.: Aus Bad Schinznachs Vergangenheit. Aarau.

16. Gotthelf, J. (Albert Bitzius): Die Wassernot im Emmental. Sämtliche Werke, Bd. 15, Zürich 1925.

17. Guggenbühl, K.: Das Linthwerk. Zschr. Schw. Statistik. 41. Jahrg. Bern 1905.

18. Guyan, W. U.: Mensch und Urlandschaft der Schweiz. Zürich 1954.

19. Gysel, G.: Das Kraftwerk Wildegg-Brugg. Schw. Bauzeitung 1956.
20. Härry, A.: Die Entwicklung der Ausnutzung der schweizerischen Wasserkräfte. Wasserwirtschaft in der Schweiz. Bern 1914.

21. Hauri, C.: Wasserkraftnutzung. Mitt., Aarg. Natf. Ges. XXIV, 1953.

22. Heinemann, V.: Bad Schinznach. Hist. Rückblick. Brugger Neujahrsblätter 1950.

23. Heller, H.: Struktur und Dynamik von Auenwäldern. Beitr. geobot. Landesaufnahme der Schweiz, Heft 44, 1963.

24. Hiltbrunner, H.: Auenwälder. Brugger Neujahrsblätter 1950 .

25. Huizinga, J.: Wenn die Waffen schweigen. Die Aussichten auf Genesung unserer Kultur. Zürich 1945.

26. Jäckli, H.: Die Beziehungen zwischen Mensch und Geologie. Wasser- und Energiewirtschaft, Sonderheft Linth-Limmat, 1962.

27. - Der Mensch als geologischer Faktor. 250 Jahre Kanderdurchstich. Geogr. Helv. 1964.

28. Kaiser, S. und Strickler, J.: Geschichte und Texte der Bundesverfassungen der schweiz. Eidgenossenschaft von der helv. Staatsumwälzung bis zur Gegenwart. Bern 1901.

29. Käppeli, R.: Es war auf kurze Zeit geborgt. Sondernummer Wasser, Cibablätter 174, 1961.

30. Koch: Bericht der Schwellenkommission über die Correction der Aar von Thun bis Bern. Bern 1826.

31. Moor, M.: Pflanzengesellschaften schweizerischer Flußauen. Mitt. schw. Anst. forstl. Versuchswesen 34, 1958. (Nr. 3 des Fonds für Flußauenforschung.)

32. Morlot, v.: Flußkorrektionen der Schweiz. Schweiz. Oberbauinspektorat, Heft 5, Bern 1916.

33. Müller, M.: Aueböden des Schweizerischen Mittellandes. Mitt. schweiz. Anst. forstl. Versuchswesen 34, 1958. (Nr. 2 des Fonds für Flußauenforschung.)

34. Oesterhaus, M. und Walser, E.: Von der Notwendigkeit einer zielbewußten Ordnung aller menschlichen Einwirkungen auf das Wasser. Mitt. schw. Anst. forstl. Versuchswesen 35.

34. a Peter, A.: Die Juragewässerkorrektion. Bern 1922.

35. Ramser, E.: Auswirkungen der Meliorationen auf Klima, Niederschläge und Nebelbildung. Melioration der Linthebene. 9. Rapport der Eidg. Kommission. Lachen 1952.

36. Regierungsrat d. Kts. Aargau: Botschaft an den Großen Rat. Übertragung der Konzession für das Aarekraftwerk Wildegg-Brugg. Aarau 1947.

37. Salis, A. v.: Das schweizerische Wasserbauwesen. Bern 1883.

38. Siegrist, R.: Die Auenwälder der Aare. Mitt. Aarg. Natf. Ges. Heft XIII, 1913.

39. - Die Flußschotter der Eiszeit im Aargau und ihre natürliche pflanzliche Besiedlungsmöglich- 
keit. Mitt. Aarg. Natf. Ges. Heft XXIV, 1953. (Nr. 1 des Fonds für Flußauenforschung.)

40. - Die letzten Sanddornbestände an der untern Aare. Mitt. Aarg. Natf. Ges. Heft XVIII, 1928.

41. - Die Aare bei Klingnau. (Nr. 4 des Fonds für Flußauenforschung), Zürich 1962.

42. Stauffer, H. U.: Die aargauische Reußebene als Wohngebiet aussterbender Sumpf- und Wasserpflanzen. Ber. Geobot. Inst. Rübel, 1960.

43. Stürler, M. v.: UUber die Wasser-, Schachen- und Schwellenverhältnisse im Stromgebiet der Emme. Bern 1871.

44. Walser, E.: Wasserhaushalt der Schweiz. Wasser und Boden 2, 1962.

Les rives marécageuses des fleuves dans le paysage humanisé suisse

Le développement des rives marésageuses des fleuves de l'état naturel jusqu'à l'état actuel s'est effectué en 5 étapes:

1. Jusq'au $18 \mathrm{e}$ siècle, l'exploitation des rives marécageuses d'un fleuve se limitait à la culture des parties arables et à l'abattage des parties boisées. La plupart des constructions de protection étaient peu efficaces et de faible importance:
45. Walser, E.: Das Linth-Limmat-Gebiet in hydrographischer Sicht. Wasser- und Energiewirtschaft, Sonderheft Linth-Limmat, 1962.

46. Walser, E. und Lanker, E.: Niederschlags- und Abflußverhältnisse im Einzugsgebiet der Aare unter besonderer Berücksichtigung des Einflusses der Speicherbecken. Wasser- und Energiewirtschaft 1957.

47. Wasserwirtschaft in der Schweiz. Bern 1914.

48. Wolf, R.: Andreas Lanz. Ein Beitrag zur Geschichte der Linthunternehmung und des bernischen Kriegswesens. Berner Taschenbuch 1857. Nach Abschluß der Arbeit erschienen:

49. Hösli, J.: Wandlungen der Linthebene. Geogr. Helv. 21, 1966.

2. c'est au $18 \mathrm{e}$ et surtout au $19 \mathrm{e}$ siècle que furent effectuées les grandes corrections de la Kander, de la Linth, du Rhône, du Rhin et des eaux du Jura; 3. aux environs du $20 \mathrm{e}$ siècle commença l'exploitation des eaux par les centrales hydro-électriques; 4. après la seconde guerre mondiale commença la lutte contre la pollution des eaux;

5. aujourd'hui, nous nous voyons placés devant la tâche de conserver et de protéger les rives des fleuves avec forêts riveraines typiques et de les intégrer harmonieusement dans le paysage. 